


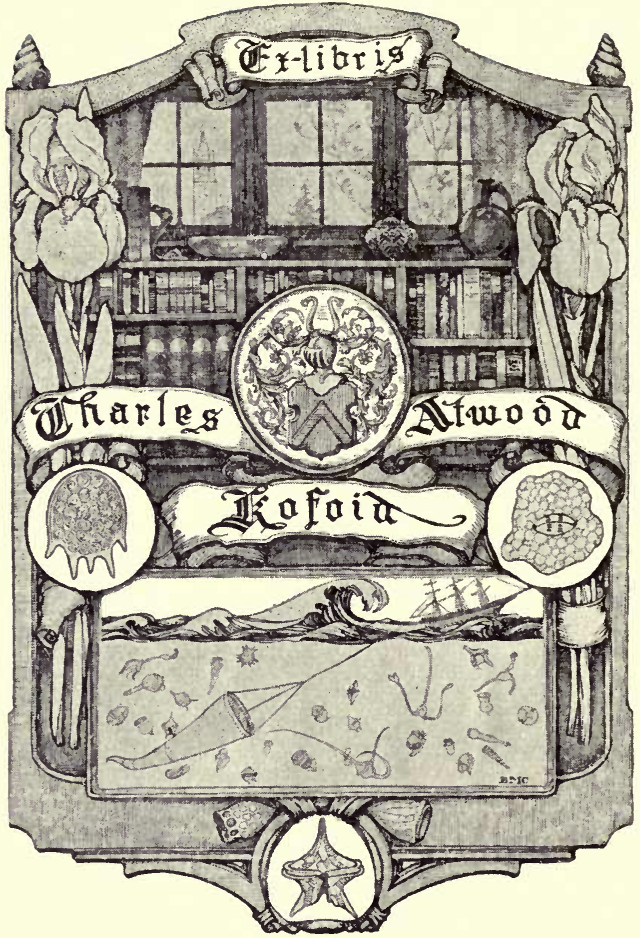




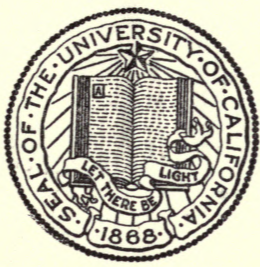

THE LIBRARY $\mathrm{OF}$

\section{THE UNIVERSITY \\ OF CALIFORNIA}

PRESENTED BY

PROF. CHARLES A. KOFOID AND MRS. PRUDENCE W. KOFOID 
THE JOHNS HOPKINS UNIVERSITY SCHOOL OF HYGIENE AND PUBLIC HEALTH

\title{
Diagnosis of ProtozoA
}

AND

\section{Worms Parasitic IN MAN}

\author{
BY \\ ROBERT W. HEGNER \\ Associate Professor of Protozoology \\ AND \\ WILLIAM W. CORT \\ Associate Professor of Helminthology \\ Department of Medical Zoology \\ School of Hrgiene and Public Health \\ The Johns Hopkins University
}

1921

BALTIMORE, MARYLAND

U. S. A. 
COMPOSED AND PRINIED AT THE

WAVERLY PRESS

By the Williams \& Wilkins Company

BALTIMORE, MD., U.S. A. 


\section{PREFACE*}

This bulletin has been prepared for the use of physicians and public health workers who are called upon to-diagnose - diseases caused by Protozoa and worms. No attempt has been made to include in the keys and descriptions all of the species that are now known. On the contrary, species that have been recorded only once or a very few times have been purposely omitted to avoid confusion.

The information and figures contained in this bulletin have been selected from original articles in periodicals, and from reference and text books wherever available. Credit for the use of figures is given in every case in the descriptions of the figures. A few of the more important books and articles relating to the parasites described are listed at the end of the account of each group. Other lists will be found in the bibliographies contained in most of these books and articles. So far as possible we have verified statements regarding the organisms described, but errors are almost certain to creep into such a compilation, and we will welcome corrections. We will also be glad to accept any suggestions for the improvement of the bulletin which may be incorporated in a second edition if called for.

The methods employed by various workers for the diagnosis of parasitic Protozoa and worms are very numerous and only a few could be described in this bulletin. These have been selected on the basis of simplicity and effectiveness. It seems to us desirable that methods applicable to field conditions and requiring the minimum of apparatus and reagents should be emphasized. Modifications of these methods may be devised to fit the circumstances encountered in the field.

* The publication of this bulletin was made possible by a grant from the International Health Board. 


\section{GENERAL LITERATURE LIST}

This general list contains titles of only a few books and periodicals selected on the basis of helpfulness and accessibility. Special lists will be found at the end of each section of the bulletin.

General Reference Books on Animal Parasites of Man Brumpt, E.: Précis de Parasitologie. 2 ed. 1011 pp. Paris, 1913.

Castellani, H., and Chalmers, H. J.: Manual of Tropical Medicine. 3 ed. $2436 \mathrm{pp}$. London, 1919.

Chandler, A. C.: Animal Parasites and Human Disease. 570 pp. New York, 1918.

Fantham, H. B., Stephens, J. W. W., and Theobald, J. F.: Animal Parasites of Man. $900 \mathrm{pp.}$ New York, 1916.

Manson, Sir Patrick: Tropical Diseases. 5 ed. $937 \mathrm{pp}$. London, 1914.

Mense: Handbuch der Tropenkrankheiten. 2 Aufl. 1915.

Neuman, R. O., and Mayer, M.: Atlas und Lehrbuch wichtiger tierischer Parasiten und ihrer Uebertrager. 580 pp. Munich, 1914.

Stitr, E. R.: Practical Bacteriology. Blood Work and Animal Parasitology. 5 ed. $559 \mathrm{pp.}$

\section{General Periodicals on Animal Parasites of Man}

Tropical Diseases Bulletin. Vol. 1, 1912, London.

Parasitology. Vol. 1, 1908, Cambridge.

Annals of Tropical Medicine and Parasitology. Vol. 1, 1907, Liverpool.

Journal of Parasitology. Vol. 1, 1914, Urbana, Illinois.

Centralblatt für Bakteriologie, Parasitenkunde, und Infectionskrankheiten. Vol. 1, Jena, 1887.

Memorias do Institute Oswaldo Cruz. Vol.1, 1909, Rio de Janeiro. Bulletin de la Societé de Pathologie Exotique. Vol. 1, 1907, Paris. Archives de Parasitologie. Vol, 1, 1898, Paris.

Archiv für Schiffs-upd Tropen-Hygiene, Vol. 1, 1897, Leipzig. 
Journal of Tropical Medicine and Hygiene. Vol. 1, 1898, London. Transactions of the Society of Tropical Medicine and Hygiene. Vol. 1, 1907, London.

Indian Journal of Medical Research. Vol. 1, 1913.

Philippine Journal of Science, Series B. Manila, 1906.

General Books and Pertodicals on Protozoology

Calkins, G. N.: Protozoology. 349 pp. Philadelphia, 1909.

Doflein, F.: Lehrbuch der Protozoenkunde. 4 ed. Jena, 1917.

Hartmann, M., and Schilling, C.: Die Pathogenen Protozoen. 462 pp. Berlin, 1917.

Minchin, E. A.: Introduction to the Study of the Protozoa. 520 pp. London, 1917.

Prowazek, S. V., and others: Handbuch der Pathogenen Protozoen. Leipzig, 1912-14.

Robert, A.: Protozoaires. Paris, 1914.

Archiv für Protistenkunde. Vol. 1-39. 1902-1919. Jena. 



\section{TABLE OF CONTENTS}

Preface.........................................

\section{Part 1. Protozoa Parasitic in Man}

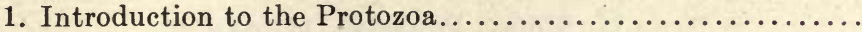

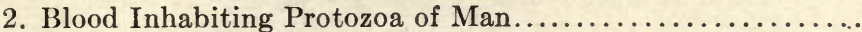

A. Organisms that cause malaria in man. 1. Classification. 2. Life history. 3. Distinguishing features of the three species of Plasmodium occurring in man. 4. Methods of making films for the diagnosis of malaria. Special literature on malaria...............

B. Organisms that cause trypanosomiasis (sleeping sickness and Chagas' disease) in man. 1. Classification. 2. Description of species. 3. Methods of diagnosis. Special literature on trypanosomiasis..............

C. Organisms that cause leishmaniasis in man. 1. Classification. 2. Description of species. 3. Methods of diagnosis. Special literature on leishmaniasis.......

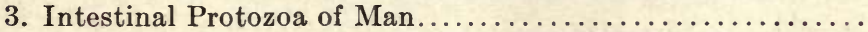

A. Methods of fecal diagnosis of intestinal protozoa. 1. Donaldson's iodin-eosin smear method. 2. Cropper and Row's concentration method. 3. Schaudinn's alcoholic sublimate iron-haematoxylin method. Special literature on methods of diagnosis of intestinal

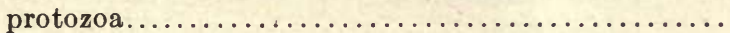

B. Intestinal Entamoebae of man. 1. Classification. 2. Species. 3. Distinguishing features (a) of motile stages and (b) of cysts. 4. Distinguishing features of cysts of intestinal amoebae of man; (a) Entamoeba histolytica. (b) Entamoeba coli. (c) Endolimax nana. Special literature on Entamoebae................

C. Intestinal Flagellates of man. 1. Classification. 2. Description of species. (a) Trichomonas hominis. (b) Chilomastix mesnili. 3. Methods of diagnosis. Special literature on intestinal flagellates..............

D. Intestinal Coccidia of man. 1. Classification. 2. Description of species. (a) Isospora hominis. (b) Eimeria wenyoni. 3. Methods of diagnosis. Special literature on Coccidia........................... 
E. Intestinal Ciliates of man. 1. Classification. 2. Description of species. (a) Balantidium coli. (b) Nyctotherus. 3. Methods of diagnosis.................

F. Some vegetable organisms in human feces. 1. Blastocystis hominis. 2. Intestinal yeasts.............

\section{Part II. Worms Parasitic in Man}

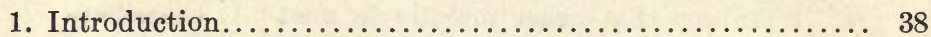

2. Diagnosis of diseases caused by parasitic worms......... 38

3. Key for diagnosis of human helminths.............. 42

4. Trematoda................................. 49

A. Definition............................. 49

B. Systematic position of human forms............. 50

C. Intestinal trematodes. 1. Fasciolopsis buskii. 2. Heterophyes heterophyes. 3. Metagonimus yokogawai...

D. Liver flukes. 1. Genus Clonorchis. 2. Opisthorchis fe-

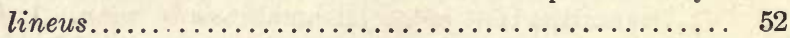

E. The lung fluke. Paragonimus westermanii......... 53

F. Blood flukes. Genus Schistosoma.............. 57

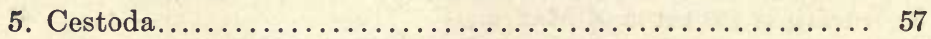

A. Definition............................ 57

B. Order Pseudophyllidea. Diphyllobothrium latum (Dibothriocephalus latus)...................... 58

C. Order Cyclophyllidea. 1. Genus Hymenolepis. 2. Genus Taenia. 3. Echinococcus granulosus (Taenia echinococcus).......................... 59

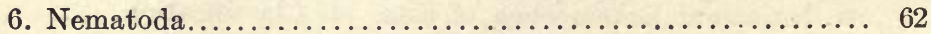

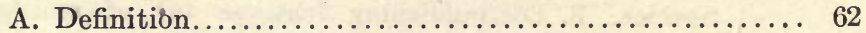

B. Family Angiostomidae. Strongyloides stercoralis...... 62

C. Family Dracunculidae. Dracunculus medinensis....... 63

D. Family Filaridae. 1. Filaria bancrofti. 2. Filaria ozzardi (Filaria demarquayi). 3. Loa loa (Filaria loa). 4. Acanthocheilonema perstans (Filaria perstans). 5. Dirofilaria magalhaesi. 6. Onchocerca volvulus....... 64

E. Family Trichinellidae. 1. Trichuris trichiura. 2. Trichinella spiralis........................ 67

F. Family Metastrongylidae.................. 68

G. Family Trichostrongylidae. Trichostrongylus orientalis 68 
H. Family Ancylostomidae. 1. Sub-family Ancylostominae. (Ancylostoma duodenale). 2. Sub-family Bunostominae. (Necator americanus)........... 69

1. Family Strongylidae...................... 70

J. Family Ascaridae. Ascaris lumbricoides ............ 71

K. Family Oxyuridae. Enterobius vermicularis.......... 72 



\section{PART I. PROTOZOA PARASITIC IN MAN}

\section{ROBERT W. HEGNER}

\section{Introduction to the Protozoa}

The Protozoa may be defined as unicellular animal organisms usually microscopic in size, but nevertheless exhibiting many activities similar to those of the higher animals, though in a simpler form. They are generally separated into four classes according to the presence or absence of locomotor organs and the character of these when present. The class Sporozoa contains only parasitic species, but the other three classes comprise both free living and parasitic forms. Species parasitic in man occur in all four classes. The following is a brief classification of the Protozoa with examples of human parasites.

Class 1. Rhizopoda. With pseudopodia. Entamoeba histolytica, E. coli, Endolimax nana.

Class 2. Mastigophora. With flagella. Giardia intestinalis, Trichomonas hominis, Trypanosoma gambiense, Leishmania donovani.

Class 3. Sporozoa. Without locomotor organs in adult stage: sporulation occurs. Plasmodium vivax, Isospora hominis.

Class 4. Infusoria. With cilia. Balantidium coli.

\section{Blood Inhabiting Protozoa of Man \\ A. Organisms that Cause Malaria in Man}

1. Classification. The organisms that cause malaria in man belong to the class Sporozoa, subclass Telosporidia, order Haemosporidia and family Plasmodidae.

The members of the class Sporozoa are parasitic Protozoa without locomotor organs and are further characterized by the method of reproduction known as sporulation. In the subclass Telosporidia the vegetative (trophic) stage precedes 
and is separate from the sporulation stage. The members of the order Haemosporidia are intracellular in the trophozoite stage, have no resistant spores and undergo an alternation of schizogony in a vertebrate and sporogony in a blood sucking invertebrate (e.g. mosquito). To the family Plasmodidae belong the genera Haemocystidium which occurs in reptiles, and Plasmodium which includes the malarial organisms. Three species of Plasmodium are known from man, (1) $P$. vivax, which causes tertian malaria, (2) $P$. malariae, which causes quartan malaria, and (3) P. falciparum, which causes aestivo-autumnal malaria. Malarial organisms also inhabit lower animals, such as $P$. danilewskyi in birds, $P$. kochi in chimpanzees, $P$. bovis in cattle, $P$. canis in dogs, $P$. equi in horses and $P$. diploglossi in lizards. In the accompanying table the distinguishing features of the three species of Plasmodium occurring in man are contrasted as an aid in identification.

2. Life history (Plate I). Certain species of mosquitoes of the genus Anopheles are the transmitting agents of the malarial organisms of man. Infective mosquitoes carry the organisms in their salivary glands; from here they pass into the blood of any animal the mosquito bites. The stages in the life history of the tertian parasite, Plasmodium vivax are briefly as follows:

a. Sporozoite: a falciform body about 14 microns long, present in infective mosquitoes; the stage that is inoculated into man. The sporozoites enter red blood cells, usually only one to a cell, where they become amoeboid in shape.

$b$. Trophozoite: the first stage in the red blood cell, at first ring shaped, later amoeboid, and finally circular or oval in outline. The trophozoites develop into either schizonts or gametocytes.

c. Schizont: a stage that develops from a trophozoite, and undergoes segmentation into from 15 to 20 spores known as merozoites. 


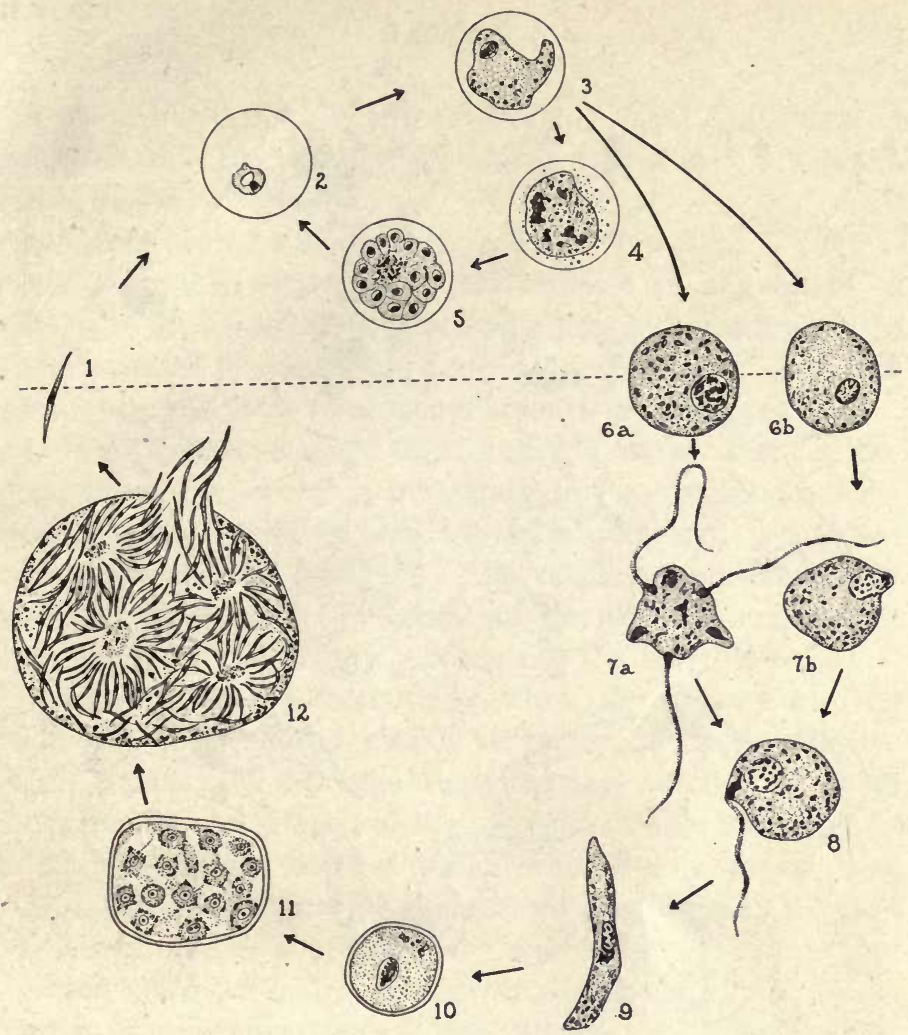

\section{PLATE I}

Life-Cycle of the Tertian Malarial Organlsm, Plasmodium vivax

The stages above the dotted line occur in the peripheral blood of man, whereas those below are found only in the mosquito.

1. Sporozoite. 2. Trophozoite, in red cell. 3. Full-grown schizont. 4. Schizont with chromatin in several masses. 5. Segmentation stage. 6a. Male gametocyte. $6 \mathrm{~b}$. Female gametocyte. 7a. Exflagellation of male gametocyte -formation of microgametes. 7b. Female gametocyte extruding chromatin from nucleus. 8 . Fertilization of macrogamete by microgamete. 9. Ookinete. 10. Young oocyst. 11. Oocyst with sporoblasts forming. 12. Ripe oocyst discharging sporozoites. 

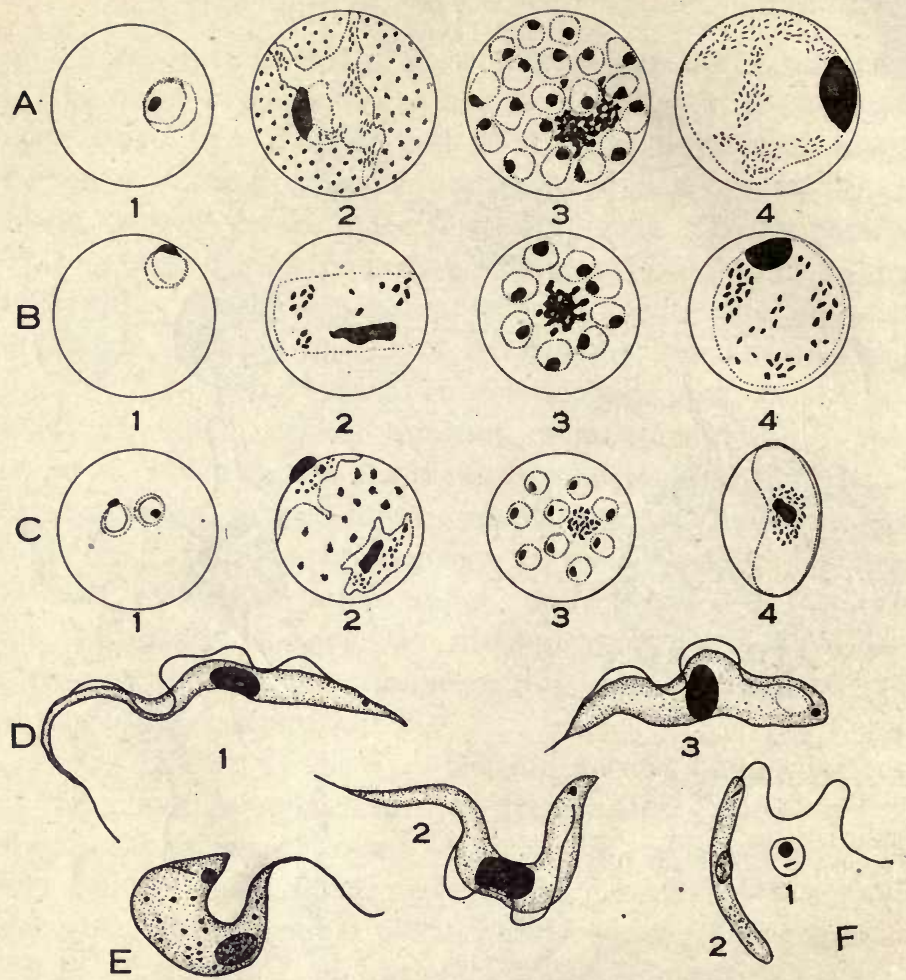

\section{PLATE II}

Blood Inhabiting Protozoa of Man

A. 1 to 4 . Plasmodium vivax.

B. 1 to 4 . P. malariae.

C. 1 to 4. P. falciparum. (1) Young trophozoite. (2) Older trophozoite. (3) Presegmentation stage. (4) Gametocyte.

D. 1 to 3. Trypanosoma gambiense. (1) Long form. (2) Intermediate form. (3) Short form. (After Castellani and Chalmers.)

E. Trypanosoma cruzi. (After Brumpt.)

F. 1. Leishmania donovani. (After Brumpt.)

- F. 2. L. tropica. (After Row.)

Figures D, E and F are magnified 1400 diameters. 
d. Merozoite: minute amoeboid spores that are liberated from the red blood cells containing segmented schizonts, and attack new red cells.

$e$. Gametocyte: a stage that may develop from a trophozoite. It does not segment but remains in the blood of man until it degenerates or is sucked up by a mosquito. In the stomach of the mosquito certain gametocytes change into macrogametes; others produce filamentous microgametes.

$f$. Fertilization: a stage that occurs in the stomach of the mosquito during which a microgamete fuses with a macrogamete. The resultant cell becomes a motile, vermiform stage known as an ookinete. The ookinete penetrates the wall of the stomach, becomes an oocyst and causes the formation of a swelling projecting into the body cavity.

g. Oocyst: a spherical body that develops from the ookinete. It produces within it hundreds of sporozoites which break out into the body cavity. Many of these reach the salivary glands of the mosquito where they remain until transferred to another animal when the mosquito bites.

The periods occupied by the various stages are as follows: (a) Growth from sporozoite or merozoite to full grown schizont-30 hours; (b) segmentation-18 hours; (c) development in mosquito from gametocytes to oocysts - 40 hours; (d) from oocysts to sporozoites -4 or 5 days. The asexual cycle of Plasmodium vivax in man is 48 hours. The mosquitoes become infective about 8 days after they suck up gametocytes. The principal differences between Plasmodium vivax and $P$. malariae and $P$. falciparum are indicated in the accompanying table (B).

4. Methods of making. films for the diagnosis of malaria. 1. Thin films. a. Equipment: Clean glass slides; small bottle of alcohol; small package absorbent cotton; Hagedorn needle fastened in cork of small vial and extending down into alcohol. 
MALARIA

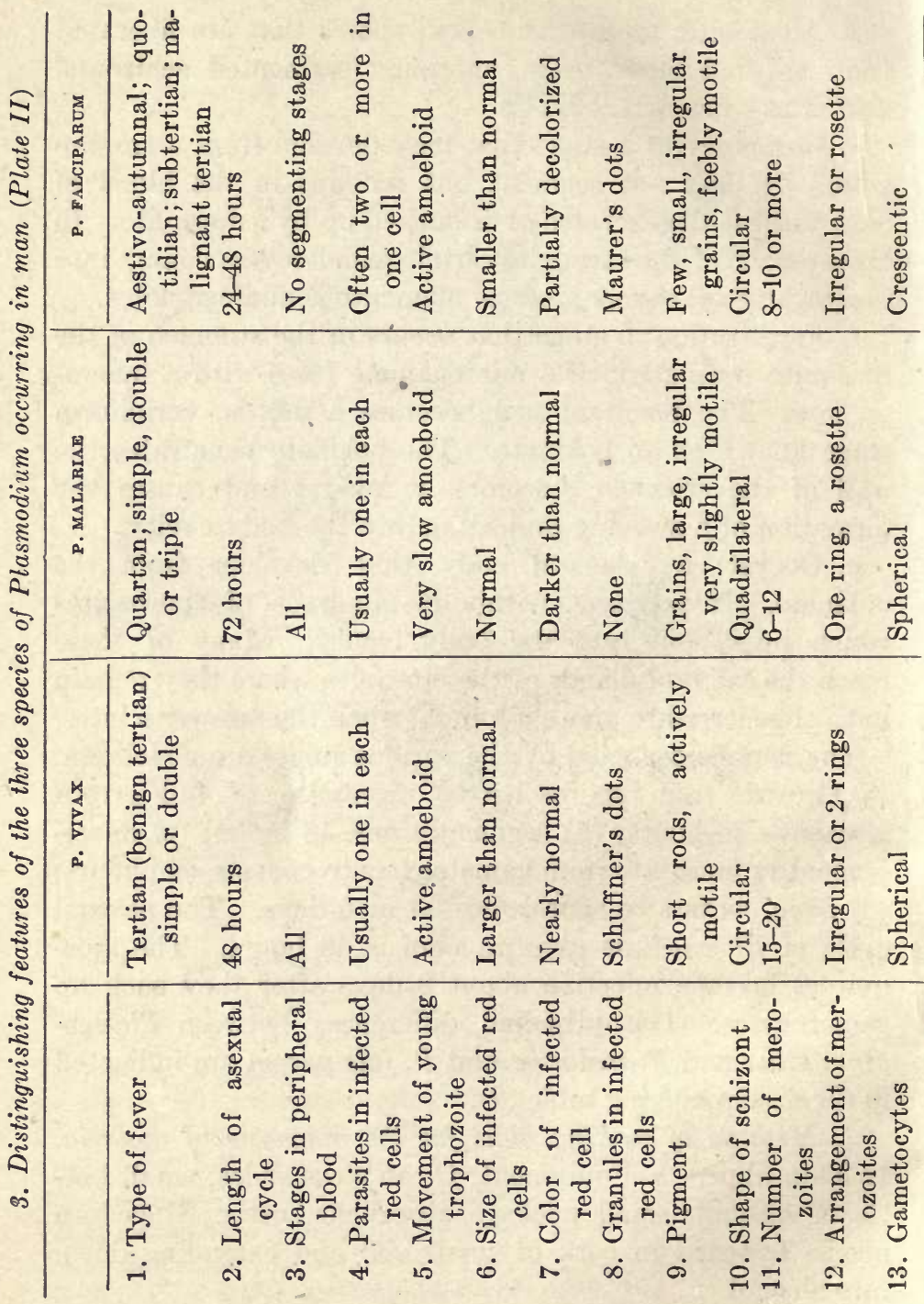


$b$. Obtaining blood: Clean ear lobe or end of finger with alcohol. Puncture with needle. One drop of blood is mounted one half inch from the end of the slide. Place the end of another slide near the drop of blood at an angle of 30 degrees to 45 degrees with the shorter end of the slide. Draw this slide along until it touches the drop. When the blood has spread along the edge push the slide fairly rapidly toward the other end. A thin film will result covering about one-half of the slide. Allow the film to dry, then write data directly in it with a lead pencil.

c. Fixing and staining. (1) Wright's stain: Cover film with a few drops of the stain and allow to remain one minute. Add double the volume of distilled water. After five minutes, wash, and dry in air. The cytoplasm of the parasite stains blue and the chromatin red. The pigment remains brown, unstained.

(2) Leishman's stain: Proceed as with Wright's stain. Vary length of periods if necessary. The results are similar to those obtained by the use of Wright's stain.

(3) Giemsa's stain: Fix in absolute methyl alcohol for 5 minutes, wash gently. Stain in one part Giemsa plus ten parts distilled water for ten minutes. Wash. Dry. The results are similar to those obtained by the use of Wright's or Leishman's stains.

2. Thick films. a. Equipment: Same as for thin films.

$b$. Obtaining blood: Same as for thin films, except several drops are obtained near center of slide and spread with the needle over an area of one-half to three-fourths of an inch.

c. Fixing and staining: Fix and decolorize in 95 per cent alcohol plus 2 per cent $\mathrm{HCl}$ for one-half hour. Wash in running tap water a few minutes. Stain as with thin films. In these preparations more blood cells are present per unit area and hence the presence of parasites is more easily determined. 


\section{Special Literature on Malaria}

Ascoli, V:: La Malaria. 1127 pp. Torino, 1915.

Craig, C. F.: The Malarial Fevers, Haemoglobinuric Fever and theBlood Protozoa of Man. 477 pp. New York, 1909.

Hrndle, E.: Flies in Relation to Disease. Blood-sucking Flies. 398 pp. Cambridge, 1914.

JAmes, S. P.: Malaria at Home and Abroad. 234 pp. London, 1920.

Ross, R.: The Prevention of Malaria. 2d ed. $711 \mathrm{pp.} \mathrm{London,}$ 1911.

Zieman, H.: Die Malaria. In Mense's Handbuch der Tropenkrankheiten. Bd. 5, ed. 2, 602 pp. Leipzig, 1918.

B. Organisms that Cause Trypanosomiasis (Sleeping Sickness and Chagas' Disease) in Man

1. Classification. These diseases are caused by bloodinhabiting Protozoa known as trypanosomes. They belong to the class Mastigophora whose members are characterized by the presence of one or more permanent whip-like locomotor organs called flagella. The flagellates comprise both free-living and parasitic species. For the sake of convenience the flagellates that spend part of their life cycle in the blood of vertebrates and the other part in the digestive tract of a blood sucking invertebrate are usually termed Haemoflagellates. To this group belong the trypanosomes and leishmanias.

2. Description of species. Among the more important species of trypanosomes that are pathogenic in lawer organisms are $T$. brucei that causes nagana in mammals, $T$. evansi that causes surra in cattle, camels, etc., $T$. equiperdum that causes dourine in horses, $T$. equinum that causes "mal de caderas" in horses and dogs, and $T$. hippicum that causes murrina in mules. The number of species of trypanosomes that are pathogenic in man is not certain; those usually recognized are $T$. gambiense, $T$. rhodesiense, and $T$. cruzi. Other probable species are $T$. nigeriense and $T$. castellanii. 
a. T. gambiense (Plate II, Fig. D, 1, 2, 3). This species was named by Dutton in 1902 from specimens taken from a fever patient in Tropical Africa. It is the cause of one type of sleeping sickness. It ranges from 18 to 30 microns in length and 1.5 to 2.5 microns in width. Polymorphism is exhibited by this species there being short, stumpy forms 14 to 20 microns long, intermediate forms 20 to 24 microns long, and long forms 23 to 33 microns long. Tsetse flies of the genus Glossina transmit it from man to man.

b. T. rhodesiense. This species is so similar to T. gambiense in morphology that the two are difficult to separate. $T$. rhodesiense occurs in northwestern Rhodesia, and Portuguese and German East Africa.

c. T. cruzi (Plate II, Fig. E) causes Chagas' disease in Brazil. It is about 20 microns long and passes through a leishmania stage, especially in the muscles. The bug, Triatoma, is the transmitting agent.

3. Methods of diagnosis. Blood films should be made and stained as described for the malarial parasites (page 15). The trypanosome nature of the organism can be recognized at once but the species diagnosis is very difficult.

\section{Special Literature on Trypanosomiasis}

Laveran, A., ANd Mesnil, F.: Trypanosomes and Trypanosomiasis. 2d ed. 1000 pp. Paris, 1912.

Reports Sleeping Sickness Commission, Royal Society of London, 1903.

Sleeping Sickness Bulletin, London, 1908-1912.

Thrmm, C. A.: Bibliography of Trypanosomiasis. Sleeping Sickness Bureau, London, 1909.

\section{Organisms that Cause Leishmaniasis in Man}

1. Classification. The organisms that cause leishmaniasis are included among the Haemoflagellates, and belong to the genus Leishmania. Forms with flagella usually appear only in cultures. 
2. Description of species. Kala-azar is caused by Leishmania donovani; infantile kala-azar resembles kala-azar somewhat and is caused by a related organism, L. infantum; oriental sore is due to the presence of L. tropica; and espundia or American leishmaniasis is caused by $L$. americana.

a. L. donovani (Plate II, Fig. F, 1) occurs in many parts of India, Southern China and Northern Africa. It is found only occasionally in the blood, but usually lives within the cells of the spleen, liver, lymph glands and endothelial cells of the blood and lymph vessels. The organisms are spherical or oval in shape and vary from 2 to 4 microns in diameter. Each contains a large nucleus and a small rodshaped body. Multiplication occurs in the invaded cells, and the parasites, when they break out, are often devoured by leucocytes. When cultivated outside of the body flagellated stages appear. The bed bug has been suspected as the transmitting agent.

b. $L$. infantum may be only a variety of $L$. donovani; it exists in certain lands bordering on the Mediterranean, and frequently, attacks children. The organism resembles $L$. donovani. The transmitting agent is unknown but may be the dog flea.

c. L. tropica (Plate II, Fig. F, 2) is the causative agent of oriental sore in India, Persia, Syria, Arabia and Northern Africa. The organisms are present outside and within the cells of the sore. They are often spindle shaped and about 3 microns long. Flagellate forms have been recovered from bed-bugs 48 hours after feeding on a sore.

d. L. americana causes espundia in certain regions of tropical South America. Skin sores are produced by the attacking organisms.

3. Methods of diagnosis. $L$. donovani and $L$. infantum should be looked for in leucocytes in the circulating blood or in material obtained from spleen or liver puncture. 
$L$. tropica and $L$. americana can be obtained directly from the sores. Films should be stained as described for the malarial parasites.

\section{Special Literature on Leishmaniasis}

Laveran, A.: Leishmanioses. 521 pp. Paris, 1917.

\section{Intestinal Protozoa of Man}

\section{A. Methods. of Fecal Diagnosis of Intestinal Protozoa}

The method of fecal diagnosis employed depends somewhat on the accuracy of the results desired and the ability to obtain and use special apparatus. The Donaldson iodineosin method seems to be the quickest and easiest. Concentration methods give a slightly higher percentage of positives and the Schaudinn iron-haemotoxylin smear method is very useful in checking up doubtful cases.

1. Donaldson's iodin-eosin smear method. - a. Make up a fresh solution as follows: Saturated solution of eosin in normal salt solution, two parts; 5 per cent potassium iodid in normal salt solution saturated with iodin, one part; normal salt solution, two parts. This is a modification of Donaldson's stain, due to Kofoid, Kornhauser and Swezy.

$b$. "The smear is prepared for microscopic examination by rubbing out a minute bit of the feces by rolling it on a round applicator stick in a small drop of normal salt solution and then in an adjacent drop of iodin-eosin stain. A single cover is placed on both drops and the smear is ready for immediate examination. Living flagellates and unstained cysts appear in the unstained part. In the stained area the bacteria, fecal particles and the intestinal yeasts (except the larger forms) stain at once. Against the pink background the protozoan cysts stand out clearly as bright spherules which soon become tinged with the iodin to varying tones of yellow, 
while their glycogen filled vacuoles, when present, turn light or dark brown according to their mass. The nuclei become more clearly defined as the iodin penetrates, especially in E. [Entamoeba] coli and E. dysenteriae [histolytica]. They are detected with difficulty in this stain in $E$. [Endolimax] nana." (Kofoid, Kornhauser, and Swezy.)

2. Cropper and Row's concentration method. This method as modified by Boeck is as follows: "Take at least one gram of the stool to be examined, place it with thirty cubic centimeters of normal saline solution in the mixing glass and stir for at least ten minutes with an electric mixer such as is used at soda fountains in mixing drinks. At the end of ten minutes, while still stirring, add five cubic centimeters of ether and stir two or three minutes longer. Pour the emulsion into a separatory funnel and allow to stand for at least five to seven minutes, during which the cysts will settle to the bottom in the saline solution and debris will float in the ether above. The funnel used for this separation has a funnel-shaped bowl with steep sides contracting to a narrow neck above the turncock.

At the end of this period of standing, the saline solution, about fifteen cubic centimeters, is drawn off at the bottom of the separatory funnel into a centrifuge tube of a capacity of fifteen cubic centimeters, and is centrifuged for three minutes at 1600 revolutions per minute. The supernatant fluid is then drawn off and the residue is examined microscopically for the cysts. At this time a drop of neutral red is applied to a small amount of this residue to procure a sharper contrast between the cysts and the surrounding debris. By this method a faecal examination can be completed in twenty-five to thirty minutes."

3. Schaudinn's alcoholic sublimate iron-haematoxylin method. a. Prepare a fixing solution as follows: Saturated solution of mercuric chloride in distilled water, 200 cc.; 
95 per cent alcohol, 100 cc.; glacial acetic acid, 15 cc. Heat to $65^{\circ} \mathrm{C}$.

b. Make a smear on a slide and while still wet drop it into the warm fixing solution. Leave there for about ten minutes.

c. Immerse in 70 per cent alcohol, containing a trace of iodine 30 minutes to 24 hours; wash in water a few minutes; immerse in 3.5 to 4 per cent aqueous solution of iron alum, one to 4 hours; wash well in water; transfer to 0.5 per cent aqueous solution of haematoxylin; 4 to 24 hours.

$d$. Differentiate in $\mathbf{1 . 7 5}$ to 2 per cent iron alum solution until enough of the stain has been removed. This is best done by examining under the microscope at frequent intervals; wash well in a large amount of water; pass up through alcohols to absolute; transfer to xylol; mount in balsam.

$e$. Eosin may be used in the absolute alcohol if a counter stain is desired.

Special Literature on Methods of Diagnosis of Intestinal Protozoa

Bozcк, W. C.: A Rapid Method for the Detection of Protozoan Cysts in Mammalian Faeces. University of California Publ. in Zool., Vol. 18, pp. 145-149, 1917.

Cropper, J. W., and Row, R. W. H.: A Method of Concentrating Entamoeba Cysts in Stools. Lancet, Vol. 192, pp. 179-182, 1917.

Kofoid, C. A., Kornhauser, S. I., and Swezy, O.: Criterions for Distinguishing the Endamoeba of Amebiasis from other Organisms. Archives of Internal Medicine, Vol. 24, pp. $35-50,1919$.

\section{B. Intestinal Entamoebae of Man}

1. Classification. The Entamoebae belong to the class Sarcodina. The members of this class are characterized by the presence of locomotor organs in the form of temporary finger like projections of protoplasm called pseudopodia 
Many free-living species are common in fresh water; comparatively few species are parasitic. Of these $E$. histolytica (dysenteriae) is pathogenic and a very important cause of dysentery, especially in tropical and subtropical countries.

2. Species. The three important species of intestinal amoebae that have been found within the intestine of man are Entamosba histolytica, $F$. coli, and Endolimax nana. To diagnose intestinal disturbances and to detect carriers it is necessary to be able to distinguish both the motile stages and the cysts of the three species. Another species of Entamoeba that is of interest is $E$. gingivalis occuring in the mouth, and accused of causing pyorrhea alveolaris.

3. Distinguishing features. It is difficult to distinguish with certainty the species of intestinal amoebae from an examination of the living motile stages. The appended table presents some data that may be helpful. The most important diagnostic characteristics are the presence of ingested blood corpuscles in E. histolytica and their absence from the other species, and the distribution of the chromatin within the nuclei as revealed in preparations fixed in Schaudinn's fluid and stained with iron-haemotoxylin.

4. Distinguishing features of cysts of intestinal amoebae of man. The cysts of the Amoebae of man are more important from a diagnostic standpoint than the motile stages since they are more easily identified and occur more frequently in stools. Nevertheless the variation in size and in nuclear number is so great that care must be taken in making a hurried diagnosis and in certain cases permanent preparations stained with iron haemotoxylin are advisable. The accompanying table contrasts the characteristics of the cysts of the three principal species. As a rule no one feature is sufficient for a certain diagnosis and a combination of several is desirable. 


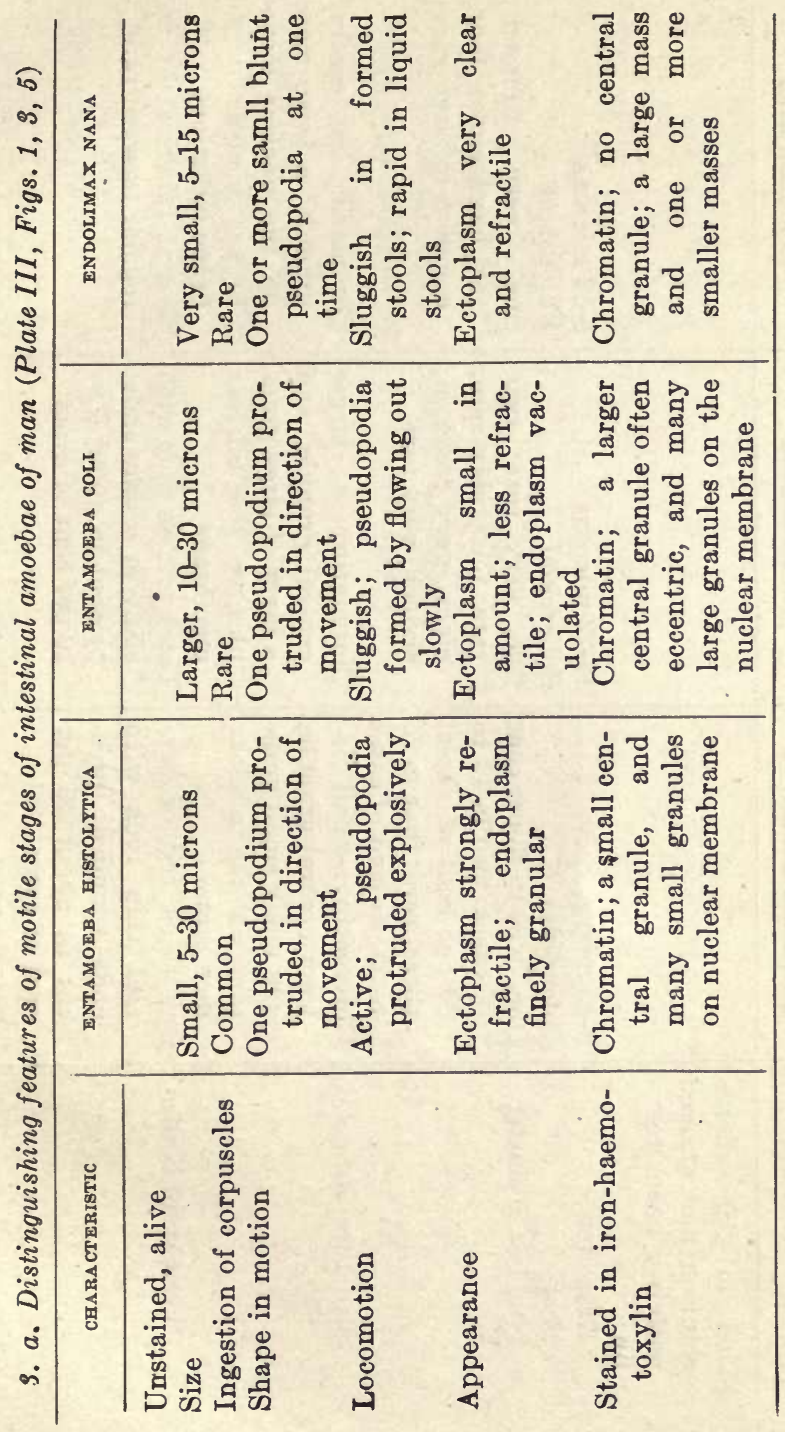




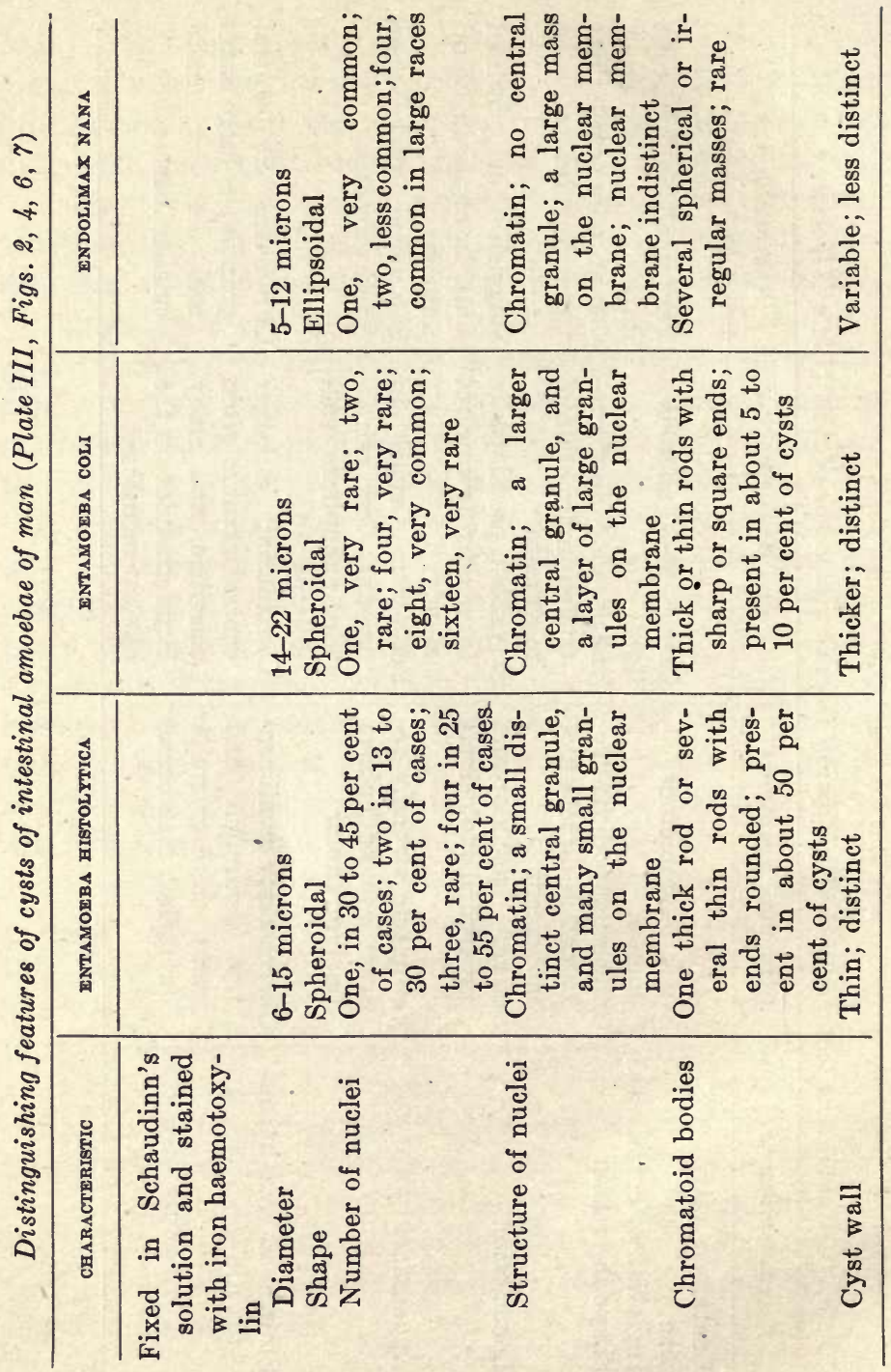




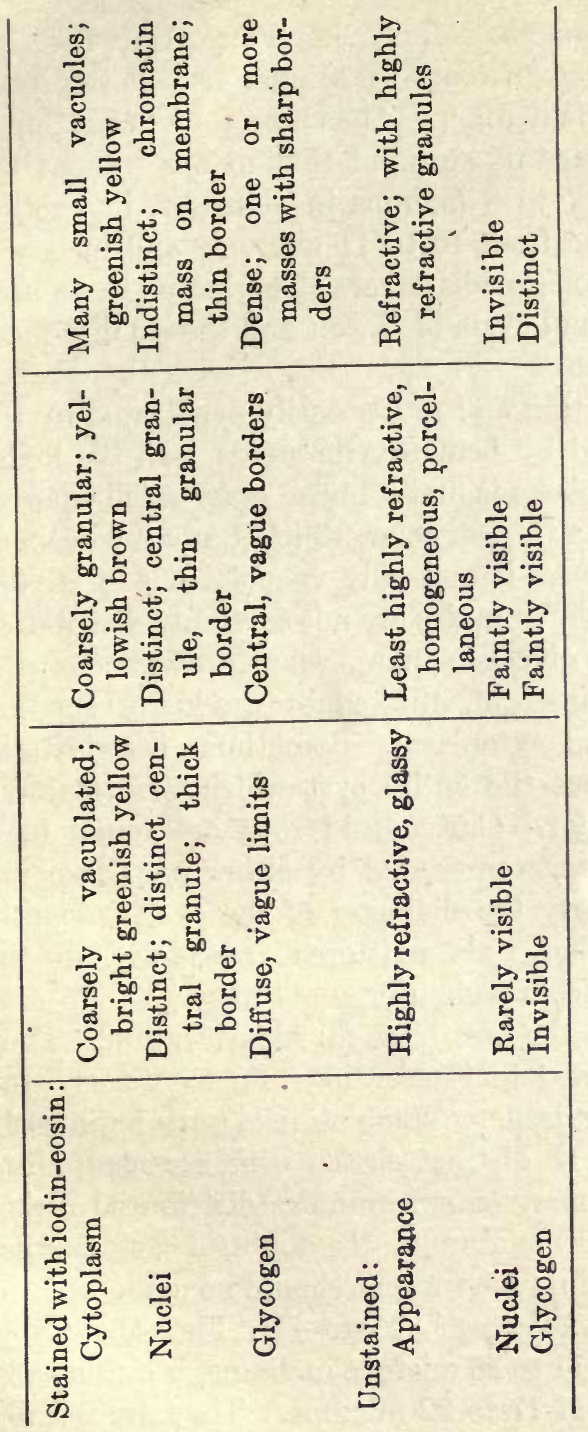


a. Cysts of Entamoeba histolytica (Plate III, Fig. 2). These vary in diameter from 5 to 20 microns but the usual range is from 6 to 15 microns. It has been found that different races exist as regards size and that in one patient the cysts may be only 7 to 8 microns in diameter, in another patient they may be from 10 to 11 microns, and in others from 12 to 14 microns in diameter. The larger races may be confused with small cysts of $E$. coli and the smaller races with cysts of $E$. nana.

"The cyst wall is thin and rather easily penetrated by the iodin-eosin stain and by hematoxylin stains. In the iodineosin stain the cytoplasm is first a bluish gray which changes to a yellow and then to a pink color, which gradually deepens to red. The cytoplasm is unevenly vacuolated and is very finely granular but the granules are not so evenly distributed as in $E$. coli. The glycogen mass, when present, stains a light brown in iodin-eosin, the edges gradually shading into the surrounding cytoplasm. Sometimes its glycogen is diffused throughout the entire cyst which then stains a yellowish brown color. Chromatoid rods are found in a majority of the cysts, represented by either one large rod with blunt ends nearly the diameter of the cyst in length, or by several smaller rods scattered irregularly in the cytoplasm." (Kofoid, Kornhauser, and Swezy.)

The nuclei furnish the best basis for identification. They range in number from 1 to 4 according to percentages listed in the accompanying table. When stained with iodin-eosin they become visible as distinct circles with a central chromatin granule, and many small granules distributed rather evenly on the nuclear membrane. In doubtful cases permanent iron haemotoxylin preparations should be made.

b. Cysts of Entamoeba coli (Plate III, Fig. 4). Cysts of $E$. coli range from 11 to 35 microns in diameter but usually lie within the limits of 17 to 22 microns. They are usually 


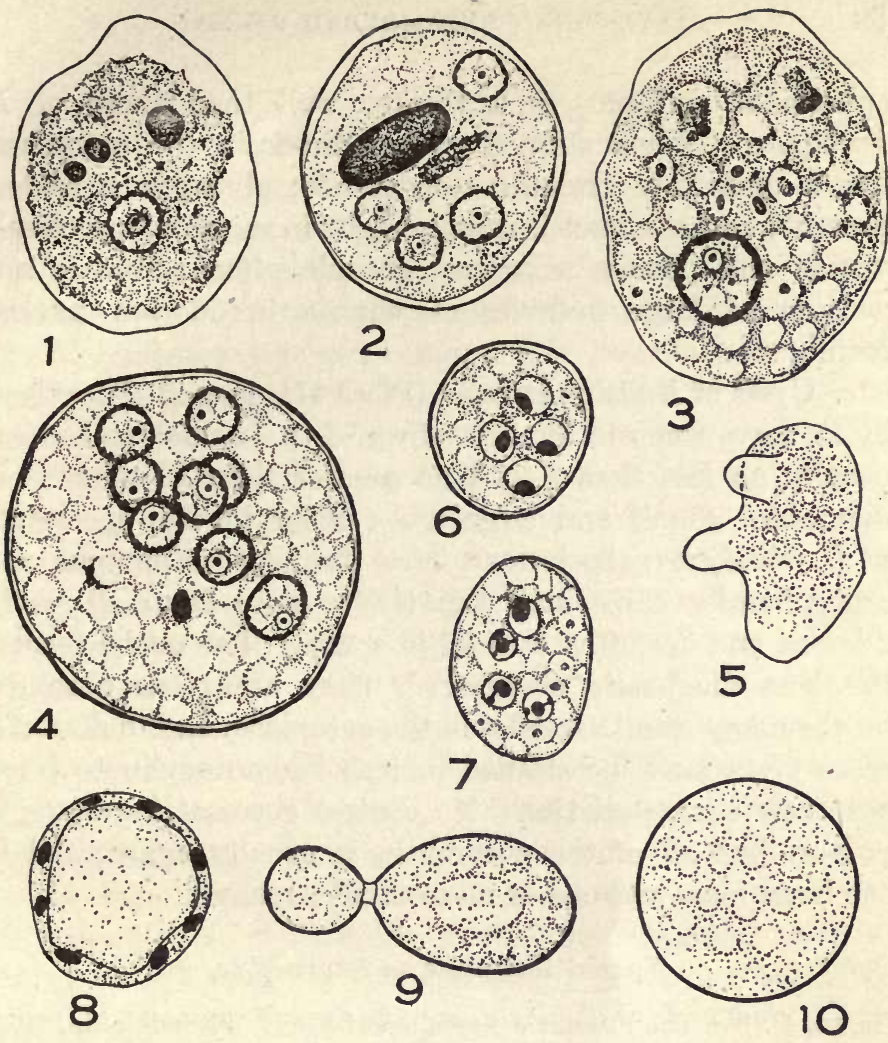

PLATE III

Intestinal Amoebae, Blastocystis, Yeast and Mold

Entamoeba histolytica. (1) Motile vegetative stage. (2) Quadrinucleate cyst with chromatoidal rod.

Entamoeba coli. (3) Motile, vegetative stage. (4) Cyst with eight nuclei.

Endolimax nana. (5) Living motile, vegetative stage. (6) Cyst with four nuclei. (7) Ellipsoidal cyst with four nuclei. (8) Blastocystis hominis, small stage. (9) Budding yeast. (10) Intestinal mold. Figs. 6, 8, 9, 10 are magnified 2800 diameters (from Kofoid, Kornhauser, and Swezy in Archives of Internal Medicine. Figures 1, 2, 3, 4, 7 (from Dobell) are magnified, $1 \times 1000,2 \times 2500$, $3 \times 1800,4 \times 2500,7 \times 2500$. 
spheroidal and possess a thicker wall than those of $E$. histolytica. When stained with iodin-eosin the cytoplasm has a uniformly granular appearance; glycogen is seldom present; and the nuclei, usually eight in number, are clearly visible and possess a central granule often eccentric and a layer of large granules of chromatin on the nuclear membrane.

c. Cysts of Endolimax nana (Plate III, Figs. 6, 7). Cysts of $E$. nana range in diameter from 3 to 16 microns but are usually no less than 5 and no greater than 12 microns in diameter. Small and large races occur in this species as in $E$. histolytica; the former vary from 4 to 8 microns and are generally ellipsoidal, the larger races from 10 to 15 microns and are often ovoidal in shape. The nuclei furnish the best diagnostic character. They are often obscured by the many small vacuoles in the cytoplasm and in doubtful cases cysts must be stained in iron haemotoxylin to bring out their characteristics. No central chromatin granule is present but all of the chromatin is usually aggregated in one large mass and one or more smaller masses.

\section{Special Literature on Entamoebae}

Crraig, C. F.: The Parasitic Amoebae of Man. Philadelphia, 1911. Dobell, C., AND Jeprs, M. W.: A Study of the Diverse Races of Entamoeba histolytica. Parasitology, Vol. 10, pp. 320-351, 1918.

Doвell, C.: The Amoebae Living in Man. 155 pp. London, 1919. Kofoid, C. A., Kornhauser, S. I., and Swezy, O.: Criterions for Distinguishing the Endamoeba of Amebiasis from Other Organisms. Archives of Internal Medicine, Vol. 24, pp. 35-50, 1919.

Wenyon, C. M., and O'Connor, F. W.: Human Intestinal Protozoa in the Near East. 218 pp. London, 1917. 


\section{Intestinal Flagellates of Man}

1. Classification. The intestinal flagellates belong to the class Mastigophora and are characterized by the presence of one or more flagella. They are representatives of two orders, (1) the Polymastigina and (2) the Protomonadina. The Polymastigina possess from 3 to 8 flagella whereas the Protomonadina have only one or two. Most of the important species belong to the former. There is great need of careful investigation of the intestinal flagellates since only a few are known at all well, and many species have been described and named but are not yet well established. The best known forms are Giardia (Lamblia) intestinalis, Trichomonas hominis, and Chilomastix (Tetramitus) mesnili. These occur so frequently that they require more extended treatment than those less well known. Among the latter are Enteromonas hominis, Embadomonas (Waskia) intestinalis, Tricercomonas hominis, Tetratrichomonas intestinalis, Pentatrichomonas intestinalis, Oicomonas hominis, Cercomonas longicauda, and Prowazekia asiatica.

2. Description of Species. a. Giardia (Lamblia) intestinalis (Plate IV, Fig. 6). Motile stage: When in the motile stage this species is pear-shaped, from 10 to 21 microns long and from 5 to 12 microns wide. The anterior half of the organism bears a depression which acts as a sucking disk for attachment to intestinal epithelial cells. Two nuclei, one or two axostyles, and four pairs of flagella are present as shown in the figure. Specimens in the motile stage are not so frequently observed in feces as are the cysts. Rats, mice and rabbits are often infected with what are probably distinct species of Giardias and those who wish to gain a preliminary knowledge of these organisms should examine material from the duodenum of these animals. 

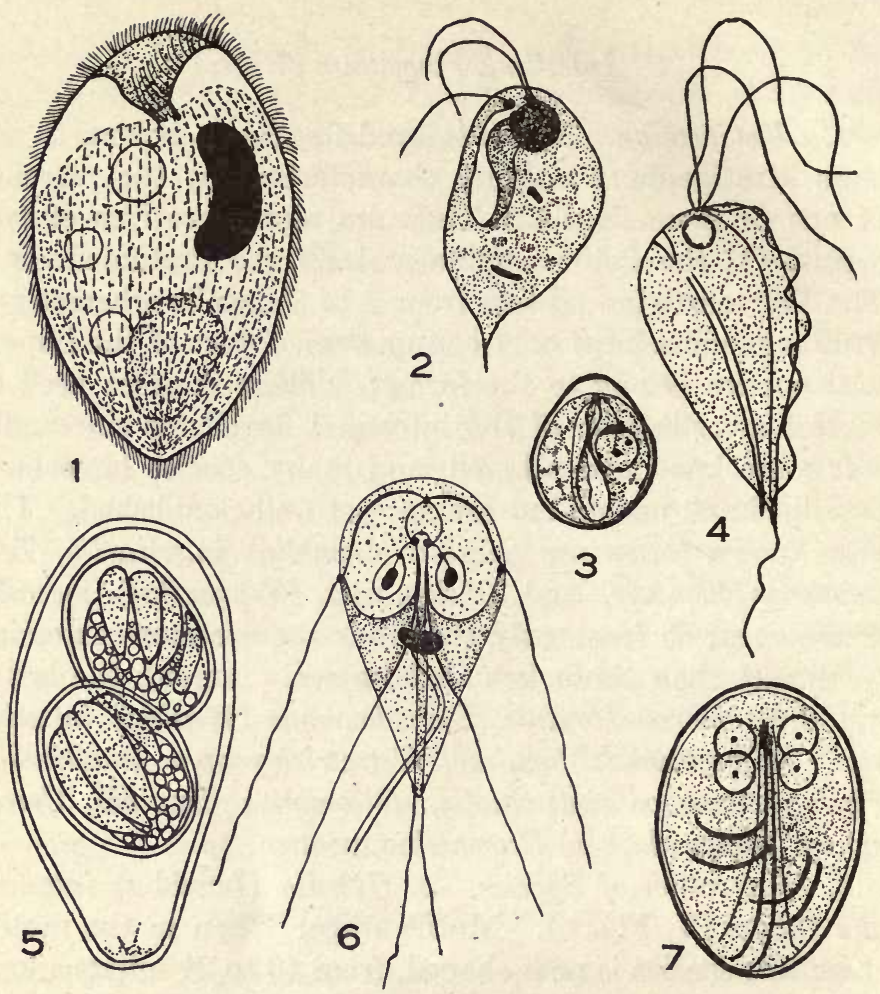

\section{PLATE IV}

Intestinal Flagellates, Ciliates and Coccidia of Man

1. Balantidium coli. ( $\times 585$, after Leuckart.) 2. Chilomastix mesnili. ( $\times 2335$, after Wenyon.) 3. Chilomastix mesnili, cyst. ( $\times 2335$ after Kofoid, Kornhauser and Swezy.) 4. Trichomonas hominis. ( $\times 2335$, after Wenyon.) 5. Isospora hominis. ( $\times 1775$, after Dobell.) 6. Giardia (Lamblia) intestinalis. ( $\times 2335$, drawn by Dr. C. E. Simon.) 7. Giardia intestinalis, cyst. ( $\times 2335$, after Kofoid, Kornhauser and Swezy.) 
Cysts (Plate IV, Fig. 7): These are oval bodies 10 to 15 microns long and 7 to 9 microns wide. Two or four nuclei are present, usually at one end, and two longitudinal curved axostyles extend down the center of the cyst. Two rodshaped parabasal bodies and a variable number of loops which probably represent the cytostomal fibrils are also embedded in the cytoplasm.

b. Trichomonas hominis (Plate IV, Fig. 4). Motile stage: This is a pear-shaped organism measuring from 10 to 15 microns long and 3 to 4 microns wide. An axostyle is situated near the center of the body and projects beyond the posterior end. Along one side is an undulating membrane terminating at the posterior end in a flagellum. Three other flagella extend out from the anterior end. The cytoplasm is vacuolated. Within it, near the anterior end are a nucleus containing scattered chromatin granules and a parabasal rod. Reproduction is by binary fission. No cysts have yet been identified with certainty. Specimens of $T$. augusta, which resemble the species found in man, are abundant in the intestine of the frog.

c. Chilomastix (Tetramitus) mesnili (Plate IV, Fig. 2). Motile stage: This may also be described as a pear-shaped organism, rounded anteriorly and pointed posteriorly. It varies considerably in size ranging from 7 to 8 microns in length. Three flagella extend out freely from the anterior end, and a fourth flagellum lies within the cytostome. The cytostome is about one-half the length of the body. A large spherical or oval nucleus lies near the anterior end.

Cysts (Plate IV, Fig. 3): These are usually pyriform but often spherical and measure 6 to 9 microns in diameter. A single nucleus is present containing a chromatin granule near the center and chromatin masses on the membrane. Extending across the cyst are the remains of the cytostome characteristic of this species. 
3. Methods of diagnosis. The motile forms of intestinal flagellates may be seen moving about in the feces if material is examined shortly after being passed by the patient. Both motile forms and cysts may appear when treated according to the methods described on page 22 .

\section{Special Literature on Intestinal Flagellates}

Chalmers, A. D., and Peknola, W.: Chilomastix mesnili. Annals Trop. Med. and Parasit. Vol. 11, pp. 213-264, 1918.

Kofoid, C. A., Kornhauser, S. I., and Swezy, O.: Criterions for Distinguishing the Endamoeba of Amoebiasis from other Organisms. Archives of Internal Medicine, Vol. 24, pp. $35-50,1919$.

Wenyon, C. M., and O'Connor, F. W.: Human Intestinal Protozoa in the Near East. 218 pp. London, 1917.

\section{Intestinal Coccidia of Man}

1. Classification. The Coccidia are Sporozoa of the subclass Telosporidia. They are as a rule parasitic in epithelial cells of vertebrates and invertebrates, and reproduce by both schizogony and sporogony. Among the best known Coccidia are Coccidium schubergi of the centipede, Eimeria stiedae of the rabbit, and $E$. avium in birds. Many other species are known, but not in detail.

2. Description of species. Prior to the year 1915 only ten cases of coccidiosis in man had been reported and these were supposed to be due to the same parasites as those found in rabbits, cats and dogs. Recently many more cases have been discovered and it seems probable that the human coccidia are more numerous than heretofore suspected.

a. Isospora hominis (Plate IV, Fig. 5). This species was first described by Virchow in 1860. Wenyon and others have recently reported over sixty cases of infection of soldiers suffering from dysentery and enteritis and invalided to England from Gallipoli. This species has also been recorded 
from men who had been in Egypt, Saloniki, and Mesopotamia.

The oocysts in the feces are elongate, ovoid in form, 25 to 33 microns in length, and 12.5 to 16 microns in width. Two sporoblasts are formed in each oocyst and each sporoblast produces four vermiform sporozoites.

b. Eimeria wenyoni was discovered by Wenyon in 1915 and four cases have been recorded. The oocyst is spherical, about 20 microns in diameter and with an outer rough surface. Within the oocyst are four sporoblasts each containing two sporozoites. These are already differentiated when the oocysts are passed by the patient.

c. Eimeria oxyspora is known from only one case. The oocyst is spherical and about 36 microns in diameter. Within it are four sporoblasts each with two sporozoites.

3. Methods of Diagnosis. The oocysts of coccidia appear when the feces are treated as described on page 88. Perhaps the best way to become acquainted with them is to examine the feces of rabbits, which are very highly infected. Freshly passed oocysts of the rabbit coccidium, Eimeria stiedae, are almost filled with protoplasm. If the feces are mixed with water the oocysts will develop and within about 48 hours four sporoblasts will form within them, each of which will be seen to contain two sporozoites.

\section{Special Literature on Coccidia}

Dobell, C.: A Revision of the Coccidia Parasitic in Man. Parasitology, Vol. 11, pp. 147-197, 1919.

Wenyon, C. M.: Observations on the Common Intestinal Protozoa of Man, Their Diagnosis and Pathogenicity. Journal Royal Army Medical Corps, Vol. 25, p. 600, 1915. 


\section{$E$. Intestinal Ciliates of Man}

1. Classification. The ciliates belong to the class Infusoria. The members of this class are characterized by the presence of locomotor organs in the form of cilia. Most of them are free living. Many parasitic species occur in vertebrates and invertebrates, but only one species, Balantidium coli, has been found with frequency in man. Other species have been recorded from man but not often enough to warrant their inclusion here.

2. Description of species. a. Balantidium coli (Plate IV, Fig. 1): This is a very large Protozoon, measuring from 60 to 100 microns in length and from 50 to 70 microns in breadth. It is oval in shape and covered with cilia arranged in parallel rows, giving it a striated appearance. The macronucleus is large and bean shaped and near it lies a small spherical micronucleus. At the anterior end is a funnel shaped peristome, and at the posterior end a terminal cytopyge (anus). Two contractile vacuoles are present. Reproduction is by binary fission. Conjugation and encystment occur.

b. Nyctotherus: Three species of this genus have been reported from man but are so rare that they need not be described here.

3. Method of diagnosis. There is nothing in fecal material that is likely to be confused with these ciliates on account of their large size and distinctive characteristics. A species that may be Balantidium coli is abundant in the intestine of the pig and another species occurs in the rectum of the frog. A species of Nyctotherus lives in the rectum of the frog and another species in the rectum of the cockroach. Anyone wishing to study these parasites can easily obtain them from these animals. 


\section{F. Some Vegetable Organisms in Human Feces}

There are many bodies that occur in human feces that may be mistaken for the motile stages or cysts of Protozoa. Of these the most confusing are probably the vegetable organisms known as Blastocystis hominis, and the yeasts.

1. Blastocystis hominis (Plate III, Fig. 8). This organism is frequently found in stools containing intestinal Protozoa and often occurs when Protozoa are absent. It is usually spheroidal in shape and very variable in size, ranging from 3 to 20 microns in diameter. The smaller specimens are often oval, with granular contents that stain yellow in iodin-eosin stain, and with a peripheral film of pink. They may easily be confused with Endolimax nana. The large specimens possess a refractive homogeneous center and an outer granular coat which contains refractive granules and stains pink in iodin-eosin stain.

2. Intestinal yeasts (Plate III, Fig. 9). Certain yeasts are normally present in human feces and may be mistaken for protozoan cysts. In the iodin-eosin stain they take on a red color at once which is sufficient to distinguish them from protozoan cysts. Some of them also are found in the process of budding. Other cyst-like bodies also occur in human feces; these may be degenerating organisms, or the spores of molds (Plate III, Fig. 10). Certain of these may correspond to what Wenyon and others have called "iodine cysts;" bodies that have been identified by Dobell as belonging to an amoeba to which the name Iodamoeba bütschlii has been given. 


\section{PART II. WORMS PARASITIC IN MAN}

\section{WILLIAM W. CORT}

\section{Introduction to the Parasitic Worms}

The endoparasitic helminths belong to the classes Trematoda and Cestoda under the phylum Platyhelminthes and to the class Nematoda under the phylum Nemathelminthes. The trematodes, commonly known as flukes, are important parasites of man especially in the Far East and Africa where they produce such dangerous diseases as bilharziasis, Japanese schistosomiasis, clonorchiasis and paragonimiasis. The cestodes or tapeworms are practically cosmopolitan in distribution. While they are frequently encountered their relation to disease is not so definite except in the case of Echinococcus, which in man produces hydatids of the liver and other organs. The nematodes or round worms are the most prevalent and important helminths of man. In this group belong the organisms which produce hookworm disease, filariasis and trichinosis. It is only since medicine and public health work have come to be considered as world problems that the diseases produced by parasitic worms have come into prominence. Since such diseases are very prevalent in the Tropics and Orient and there is constant danger of their spread into new regions with commerce and immigration, it is important that the medical man, wherever located, should be acquainted with their manifestations and methods of diagnosis, and should be able to identify the worms which produce them and know their methods of entrance into man.

\section{Diagnosis of Diseases Caused by Parasitic Worms}

In diseases produced by parasitic worms the clinical picture is usually not very clear cut and the symptoms are easily confused with those of other diseases. In infestations 
with Schistosoma haematobium and Paragonimus westermanii the eggs escape with the urine and sputum respectively, so diagnosis of these forms must be made by microscopical examination of these media. In the Filaridae, the larvae are carried from one host to another by the mosquito and diagnosis is made as in malaria by the examination of blood smears. In the majority of these diseases however, the eggs or larvae of the worms escape with the feces and an accurate diagnosis can be made by microscopical examination of the stools.

In diagnosis by fecal examination the technique used is of very great importance. The number of worms present varies greatly in the different cases and even with the best possible technique it is probable that not all cases will be detected. Since in the lighter infestations there are usually no symptoms present such individuals are usually classed as "carriers." Since with almost all the parasitic worms of man an injurious effect is produced in light infestations as well as heavy, although there may be no noticeable symptoms, and since every "carrier" is a potential spreader of the disease it would seem that the greatest possible accuracy in diagnosis is desirable. There are however other factors to be considered. Greater accuracy usually means fewer examinations. When as in hookworm campaigns the examinations to be made are many and the workers few, a compromise must be made between thoroughness and speed. Under hospital conditions where there are only a comparatively few examinations to be made it would seem to be advisable to use the slower but more critical methods. In field campaigns or surveys, however, where thousands of examinations must be made, often by microscopists who have no special scientific training, and under conditions where it is difficult to obtain or use complicated apparatus, simple, more rapid methods of examination would certainly 
be preferable. Descriptions will be given of the smear method, the centrifugation method, and the brine flotationloop method of fecal examination.

Smear method: The smear is the most direct and simple method of fecal examination. In preparing a smear a small bit of the feces to be examined is mixed with distilled or filtered water on an ordinary glass microscopical slide. The smear should be mixed in enough water so that ordinary print can be seen through it. If the smears are too dense it greatly lessens the chances of finding the eggs. The accuracy of the smear method depends on the number of slides examined. The examination of a single smear will instantly detect heavy infestations, but to detect lighter cases would require the examination of such a large number of slides that the method loses its value.

Centrifugation method: The object of centrifugation is to wash and concentrate the fecal material to be examined. Various modifications of this method have been used. All have as common features (1) the thorough mixing of a piece of fecal material, with distilled or filtered water, (2) the straining of this mixture through a sieve or piece of cheese cloth to remove larger particles, (3) the centrifugation of the suspension to concentrate the material, and (4) the making of smears of the residue for examination. Usually the sample should be washed and centrifugated about three times. The time of centrifugation should be very short because the eggs are easily thrown down. The simplest application of the centrifugation method is that used at the Immigration Hospital at Angel Island, California, for examinations of oriental immigrants. Here the sample used is about the size of the thumb, and the sediment after centrifugation is spread over the whole surface of a 1 by 3 slide and is examined without a cover glass. In the hookworm campaigns of the Rockefeller International Health 
Board in the West Indies a combination of the smear and centrifugation methods is used. Two or three smears are made from each sample to eliminate the heaviest cases and the negatives are examined after centrifugation.

The brine flotation-loop method: This technique was devised by Kofoid and Barber for the examination for hookworm disease of men in the Army from the Southern States during the war. In this method a fecal sample is thoroughly mixed with concentrated brine. The coarse float is forced below the surface with a disc of No. 0 steel wool and the container allowed to stand for about an hour for the eggs to ascend. The surface film is then looped off onto a slide and examined without a cover glass. The microscope must be focused on the surface of the drop on the slide. This method gives fine concentration and a very clear preparation for study. It is without doubt the best and quickest method of examination for hookworm eggs and when combined with a preliminary single smear to eliminate the heaviest cases can be highly recommended for use in hookworm campaigns. Unfortunately operculate eggs are not floated by this method so that it cannot be used where it is desirable to detect such forms as the liver fluke, Clonorchis sinensis, and the fish tape worm, Diphyllobothrium latum. Also it is of no value in the detection of Strongyloides stercoralis since the larvae, which in this case are found in the stools, are also not floated.

Ordinary routine fecal examinations are not sufficient to detect the presence of all types of eggs. Since the eggs of Schistosoma japonicum and especially S. mansoni are not evenly distributed throughout the stool it is necessary to take special precautions in taking the sample when examining for these forms. The eggs of Enterobius vermicularis are rarely found in routine fecal examinations, but this species offers little difficulty in diagnosis on account of the anal 
itching and the finding of mature females and eggs in the stools. The following key is included to aid in the diagnosis of the diseases produced by parasitic worms.

\section{Key for Diagnosis of Human Helminths}

A. Larvae, microfilariae, in blood (the part of the key on the microfilariae is adapted from Stitt).

1. Sheath present.

a. No periodicity.

Filaria philippinensis. Tightly fitting sheath, not flattened out beyond extremities; tail pointed and abruptly attenuated; $290 \mu$ to $320 \mu$ by $5 \mu$.

b. Periodicity.

1. Noctural periodicity.

Filaria bancrofti (Plate VI, Fig. 3). Tail pointed; sheath loose; V-spot $90 \mu$ from head; break in cells $50 \mu$ from head; $300 \mu$ by $7.5 \mu$.

2. Diurnal periodicity.

Loa loa (Filaria loa) (Plate VI, Fig. 2). Tail pointed; sheath loose; V-spot $60 \mu$ to $70 \mu$ from head; break in cells $40 \mu$ from head; $245 \mu$ by $7 \mu$.

II. Sheath absent; no periodicity.

a. Tail blunt

Acanthocheilonema perstana (Filaria perstans) (Plate

VI, Fig. 4$)$. $190 \mu$ to $200 \mu$ by $4.5 \mu$ to $5 \mu$.

b. Tail sharply pointed.

1. $200 \mu$ by $5 \mu$.

Filaria ozzardi (F. demarquayi). (Plate VI, Fig, 1).

2. $250 \mu$ to $300 \mu$ by $5 \mu$ to $7 \mu$.

- Onchocerca volvulus. Microfilariae of this species have not been seen in blood but only in lymph spaces around females.

B. Larvae in feces, rhabditiform state.

I. Length of buccal cavity only one-half the diameter of body.

Stronigyloides stercoralis (Plate VI, Fig. 8). $200 \mu$ to $250 \mu$

by $13 \mu$ to $15 \mu$; genital anlage about $30 \mu$ in length. 
II. Length of buccal cavity almost equal to diameter of body. Ancylostoma duodenale* or Necator americanus (Plate VI, Fig. 10). Expansion at the base of buccal cavity; genital anlage only $4 \mu$ to $5 \mu$ in length.

C. Eggs in urine.

Schistosoma haematobium (Plate V, Fig. 3). Large terminal spine; contain fully developed miracidium; $120 \mu$ to $150 \mu$ by $40 \mu$ to $60 \mu$.

D. Eggs in Sputum.

Paragonimus westermanii $\dagger$ (Plate V, Fig. 5). Operculate: brownish or yellowish brown in color; contains fertilized E. Eggs in Feces. ovum surrounded by yolk cells; $80 \mu$ to $100 \mu$ by $52 \mu$ to $75 \mu$

I. Operculum present.

a. Eggs under $40 \mu$ in length; contain a fully developed miracidium.

1. Operculum sharply defined with shell projecting slightly behind its edge.

(a) Opisthorchis felineusł. Size of egg $30 \mu$ by $11 \mu$.

(b) Clonorchis sinensisł (Plate V, Fig. 6). Average size of egg, $29 \mu$ by $16 \mu$.

(c) Clonorchis endemicusł. Average size of eggs $26 \mu$ by $17 \mu$.

2. Operculum not sharply defined, the shape being regularly oval.

(a). Egg brownish with thick shell.

Heterophyes heterophyes. Average size of eggs $30 \mu$ by $17 \mu$.

* Diagnosis in the case of the hookworms is usually made from eggs in the stools. In old samples sometimes the eggs will have had time to hatch and then the larvae must be carefully distinguished from those of Strongyloides stercoralis.

$\dagger$ Eggs of this form are also found in feces from swallowing of sputum by the patient.

$\ddagger$ It is difficult if not impossible in the present state of our knowledge to distinguish these three species by their eggs. Since their geographical distribution differs, the locality from which the patient comes will usually give a clue to the specific identity of the worms. 


\section{PLATE V}

Eggs of the Most Important Human Helminths

All the drawings are original except figures $7,8,9$, and 11 , which are modified from other authors. All the figures are at the same magnification.

1. Fasciolopsis buskii. 2. Schistosoma mansoni. 3. Schistosoma haematobium. 4. Schistosoma japonicum. 5. Paragonimus westermanii. 6. Clonorchis sinensis. 7. Metagonimus yokogawai. 8. Taenia saginata. 9. Taenia solium. 10. Hymenolepis nana. 11. Hymenolepis diminuta. 12. Diphyllobothrium latum (Dibothriocephalus latus). 13. Ascaris lumbricoides (egg without outer coating). 14. Ascaris lumbricoides (abnormal egg). 15. Ascaris lumbricoides. 16. Trichuris trichiura. 17 and 18. Hookworm eggs. 19. Enterobius vermicularis (Oxyuris vermicularis). 20. Oxyuris incognita. 21. Trichostrongylus orientalis. 

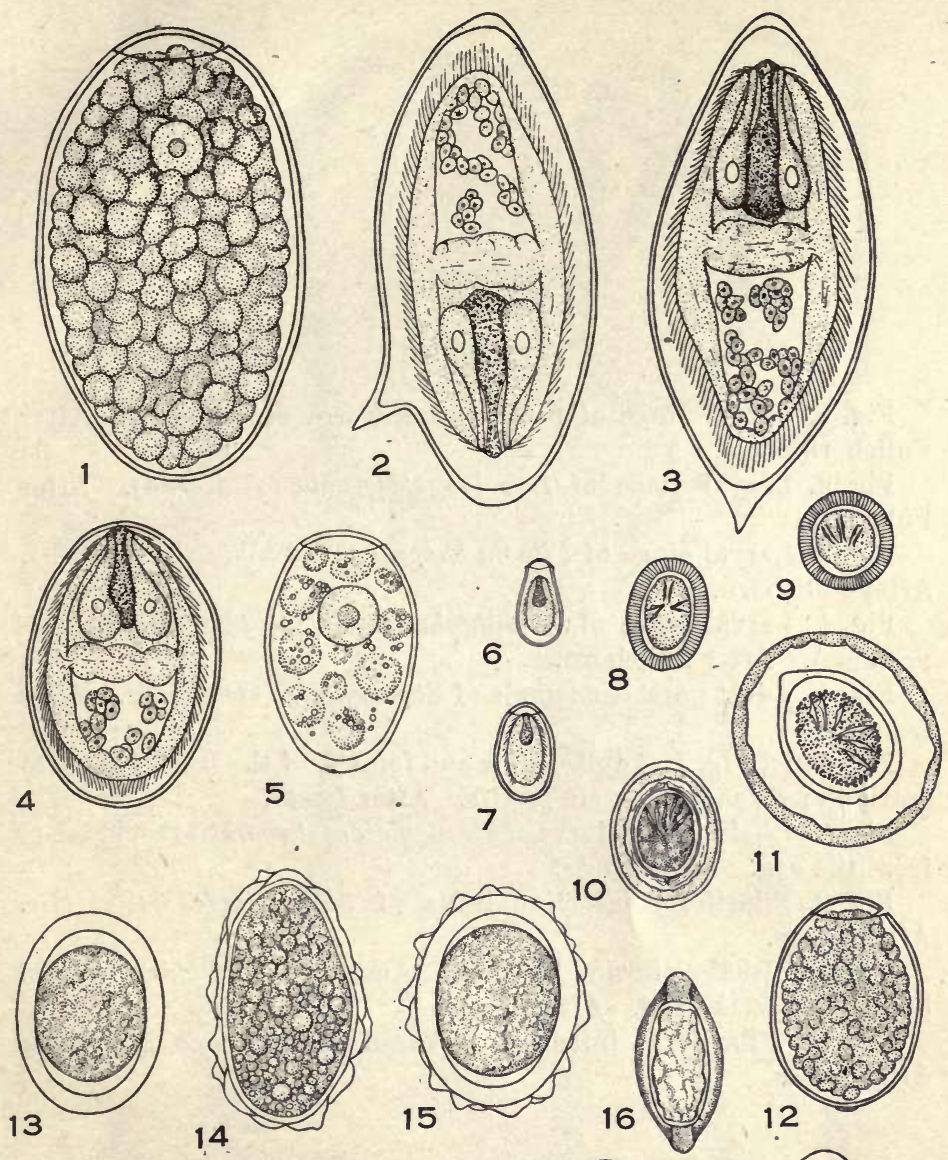

11
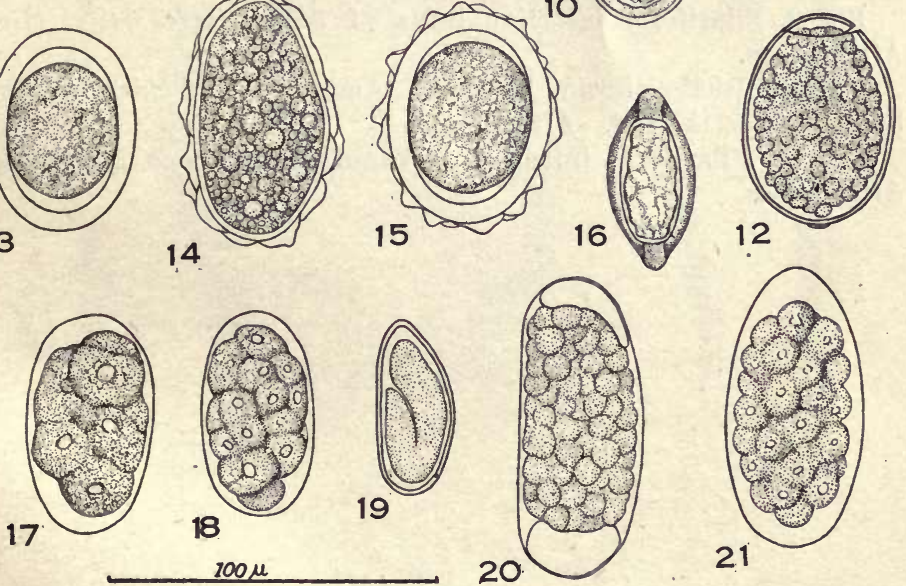


\section{PLATE VI}

Fig. 1: Larval stage of Filaria ozzardi ( $F$. demarquayi). After Fulleborn.

Fig. 2. Larval stage of Loa loa (Microfilaria diurna). After Fulleborn.

Fig. 3. Larval stage of Filaria bancrofti (Microfilaria nocturna). After Fulleborn.

Fig. 4. Larval stage of Acanthocheilonema perstans (Microfilaria perstans). After Fulleborn.

Fig. 5. Adult parasitic female of Strongyloides stercoralis. After Looss.

Fig. 6 and Fig. 7. Adults, male and female, of the free living generation of Strongyloides stercoralis. After Looss.

Fig. 8. Rhabditiform larva of Strongyloides stercoralis just hatched from the egg. After Looss.

Fig. 9. Filariform infective larva of Strongyloides stercoralis. After Looss.

Fig. 10. Rhabditiform larva of Ancylostoma duodenale just hatched from the egg. After Looss.

Fig. 11. Filariform infective larva of Ancylostoma duodenale. After Looss. 


$$
\begin{aligned}
& L[8] \\
& j(5)
\end{aligned}
$$


(b) Egg yellowish with rather thin shell. Metagonimus yokogawai (Plate V, Fig. 7). Average size of eggs $28 \mu$ by $16 \mu$.

b. Eggs over $50 \mu$ in length; do not contain a fully developed embryo.

1. Paragonimus westermanii§. (Plate V, Fig. 5). Size of egg $80 \mu$ to $100 \mu$ by $52 \mu$ to $75 \mu$.

2. Fasciolopsis buskii** (Plate V, Fig. 1). Size of egg $120 \mu$ to $130 \mu$ by $77 \mu$ to $80 \mu$.

3. Gastrodiscoides hominis (Gastrodiscus hominus). Size of egg $150 \mu$ by $72 \mu$.

4. Diphyllobothrium latum (Dibothriocephalus lătus) (Plate V, Fig. 12). Size of egg $55 \mu$ to $76 \mu$ by $41 \mu$ to $56 \mu$; operculum small not sharply defined. Shell thin transparent, light straw color.

II. Operculum absent.

a. Round or slightly oval, containing a six-hooked embryo.

1. With a thick radially striated, inner shell or embryophore.

(a) Taenia saginata (Plate V, Fig. 8). Embryophore, ovoid, rusty brown, $35 \mu$ to $40 \mu$ in length by $20 \mu$ to $30 \mu$ in width.

(b) Taenia solium (Plate V, Fig. 9). Embryophore almost round; brown, $31 \mu$ to $36 \mu$ in diameter.

2. With thin membranous inner shell.

(a) Hymenolepis nana (Plate V, Fig. 10). Oval or globular, with two distinct membranes; outer $30 \mu$ to $60 \mu$ in diameter; inner $16 \mu$ to $34 \mu$, filiform projections at each pole of inner membrane.

(b) Hymenolepis diminuta (Plate V, Fig. 11) Round or oval; outer membrane $54 \mu$ to $86 \mu$; yellowish, may be striated; inner membrane $24 \mu$ to $40 \mu$ by $36 \mu$.

$\S$ The eggs of this species are found only occasionally in feces since in man they are usually expelled with the sputum.

** The distinction between the various species of the genus Fasciolopsis described from man are so doubtful that only one is included - in the key. 
b. Shape, oval, considerably longer than wide.

1. Somewhat barrel shaped; with plugs at each end. Trichuris trichiura (Plate V, Fig. 16). Color of eggs dark brown; $50 \mu$ to $57 \mu$ by $23 \mu$; ovum unsegmented.

2. Thick transparent shell with an external albuminous coating which forms protuberances. A scaris lumbricoides (Plate V, Figs. 13, 14, 15). Color of eggs brown; $50 \mu$ to $70 \mu$ by $40 \mu$ to $50 \mu$; ovum unsegmented.

3. Asymmetrical, flattened on one side.

(a) Enterobius vermicularis (Plate V, Fig. 19). Color transparent; contains tadpole like embryo; size of egg $50 \mu$ to $55 \mu$ by $16 \mu$ to $24 \mu$.

(b) Oxyuris incognita (Plate V, Fig. 20). Oil globules at each end of egg; average size of egg $95 \mu$ by $40 \mu$.

4. Shell thin, transparent; embryo in four to many cell stages.

(a) Trichostrongylus orientalis (Plate V, Fig.

21). Ends somewhat pointed; size $75 \mu$ to $90 \mu$ by $39 \mu$ to $47 \mu$.

(b) Necator americanus. Size $58 \mu$ to $80 \mu$ by $35 \mu$ to $52 \mu$.

(c) Ancylostoma duodenale (Plate V, Figs. 17-

18). Size $56 \mu$ to $61 \mu$ by $34 \mu$ to $38 \mu$.

\section{Trematoda}

\section{A. Definition}

Parasitic Platyhelminthes; cilia present only in larval stage; adults always covered with cuticula; suckers present for attachment; digestive system without anus, usually bifurcated; development by metamorphosis or alternation of generations; adults parasitic in vertebrates. 


\section{B. Systematic Position of Human Forms}

All human trematodes belong to the sub-class Digenea, which are endoparasitic, have an alternation of generations and a molluscan intermediate host. Two of the human trematodes Gastrodiscoides hominis (Gastrodiscus hominis) and Watsonius watsoni belong to the group Amphistomata, which is characterised by the presence of a large acetabulum at the posterior end. All of the other human trematodes belong to the group Distomata, in which the acetabulum is ventral and separated from the posterior end by all or part of the reproductive system. The human trematodes will be considered according to their position in the human host.

\section{Intestinal Trematodes}

Until recently but little has been known in regard to the intestinal trematodes of man. The two amphistomes, Gastrodiscoides (Gastrodiscus) hominis and Watsonius watsoni, have been reported only a few times from man, the former from Africa and the latter from Assam and India. Their structure has been carefully worked out, but nothing is known of their life histories and method of entrance into man. Three echinostomes, i.e., distomes with a circumoral ring of prominent spines, have also been reported from the intestine of man. Of these species Echinostoma ilocanum was found in the Philippine Islands, Euparyphium malayanum (Echinostoma malayanum) in the Malay States and Artyfechinostomum sufrartyfex in India. These last two forms may belong to the same species. Three other intestinal flukes of man Fasciolopsis buskii, Heterophyes heterophyes and Metagonimus yokogawai are of sufficient importance to require further description. 
1. Fasciolopsis buskii. Large thick brown trematode; length $24 \mathrm{~mm}$. to $70 \mathrm{~mm}$. breadth $5.5 \mathrm{~mm}$. to $14 \mathrm{~mm}$.; no cephalic cone present; intestinal ceca unbranched; ovary and testes greatly branched; acetabulum larger than oral sucker, near anterior end; genital pore just in front of acetabulum; cirrus sac very long, about one-fourth body length; intestine of pig and man; life history and method of entrance into man unknown; produces intestinal disturbances; reported from India, Siam, China, Cochin China, Assam, Sumatra; common in some regions in man and pig.

Four other species of this genus, Fasciolopsis rathouisi, goddardi, fulleborni and spinifera, have been reported from man by various authors. They have been separated on minor structural differences and the true number of distinct species is still in doubt.

2. Heterophyes heterophyes. Very small, pear-shaped; length up to $2 \mathrm{~mm}$. breadth $0.4 \mathrm{~mm}$. to $1 \mathrm{~mm}$.; body covered with tiny serrate scales; acetabulum much larger than oral sucker; genital pore just behind the acetabulum, to the side and surrounded by a very characteristic annular muscular elevation, provided with 75 to 80 branched chitinous hooks; habitat small intestine; life history and method of entrance into man unknown; pathogenicity probably nil; reported in man from Egypt, Japan and China, from dogs and cats in Egypt, Japan and Formosa.

Another species of this genus, Heterophyes nocens has been described in man from Japan. This form is smaller than H. heterophyes and differs in structural details. The encysted stage is found in fish, man being infected from eating raw or imperfectly cooked fish.

3. Metagonimus yokogawai. Very small form; length 1.5 $\mathrm{mm}$. to $2.5 \mathrm{~mm}$., width $0.4 \mathrm{~mm}$. to $0.7 \mathrm{~mm}$.; surface of body covered with nail shaped spines, about $10 \mu$ in length; acetabulum sac-like, placed deeply in the body and opening 
dextro-laterally; genital pore opens into a genital sinus which opens into a pit in front of the ventral sucker; the openings of the genital sinus and of the ventral sucker are furnished with complex muscular apparatus; found usually in upper or middle portion of jejunum, rarely in caecum; cercaria develops in redia in fresh water snail, Melania libertina; encysted stage in muscles of fish, especially trout, Plecoglossus altivelus; man infected by eating uncooked fish containing larvae; may cause chronic intestinal catarrh and frequently destroys intestinal glands; found in Japan, Korea, Formosa and China in man, dog and cat.

\section{Liver Flukes}

The large sheep liver fluke, Fasciola hepatica, a closely related species $F$. gigantica and the lancet fluke of sheep, Dicrocoelium dendriticum have been reported as incidental parasites of man. All the other human liver flukes, belong to the family Opisthorchiidae, the representatives of which are common in fish eating mammals. The only species of medical importance are Opisthorchis felineus, Clonorchis sinensis and $C$. endemicus. Some authors consider that the last two forms represent but one species. In this outline they will be considered, as separate species. Opisthorchis viverrini, a common parasite of the Indian civet cat, has been reported incidentally in man from Chiengmai, Siam. Another species, Amphimerus noverca, has been found once in man in Calcutta, India.

1. Genus Clonorchis. Medium sized flukes; anterior extremity somewhat pointed; body thin and transparent; cuticula smooth; suckers small and weak, acetabulum being smaller than oral sucker; testes situated one behind the other at posterior end and very much branched; ovary and seminal receptacle small, median, just in front of testes; coils of uterus fill space between ovary, and acetabulum; habitat in bile ducts of man, cat, dog, etc. 
Clonorchis sinensis (Plate VII, Clonorchis endemicus

Fig. 1).

Length, $13 \mathrm{~mm}$. to $22 \mathrm{~mm}$.

Width, $3 \mathrm{~mm}$. to $4 \mathrm{~mm}$.

Parenchyma contains numerous yellowish or brownish pigment granules

Vitellaria interrupted

Eggs, length $26 \mu$ to $30 \mu$ by $15 \mu$ to $17 \mu$. Average size $29 \mu$ by $16 \mu$

Distribution, China, Cochin China, Formosa

Life history unknown, probably very similar to that of Clonorchis endemicus

Pathogenicity. Produces severe chronic disturbances of the liver

Length $6 \mathrm{~mm}$. to $15 \mathrm{~mm}$.

Width $1.8 \mathrm{~mm}$. to $2.6 \mathrm{~mm}$.

Parenchyma contains no pigment.

Vitellaria continuous

Egg. Average size $26 \mu$ by $15 \mu$

Distribution Japan, Korea, Cochin China

Life history: Cercaria develops in redia in a small fresh water snail, Bythinia striatula var. Japonica; encysted stages are found in a number of species of fresh water fish

Pathogenicity. The same as in Clonorchis sinensis

2. Opisthorchis felineus. Yellowish red, flat, transparent fluke; length $8 \mathrm{~mm}$. to $11 \mathrm{~mm}$., width $1.5 \mathrm{~mm}$. to $2 \mathrm{~mm}$.; testes lobed, obliquely one behind the other, in posterior fourth of body; ovary small, slightly lobed, just in front of testes; uterus fills median field between ovary and ventral sucker; habitat gall bladder and bile ducts of cats, dogs, fox and man; encysted stage in fresh water fish; found in man not infrequently in Russia, Siberia and East Prussia. Pathogenicity similar to that of Clonorchis sinensis.

\section{E. The Lung Fluke}

A single species of trematode, Paragonimus westermanii, is found in the lungs of man; a closely related species Paragonimus kellicotti from the lungs of the pig and cat have also been described from the United States. 


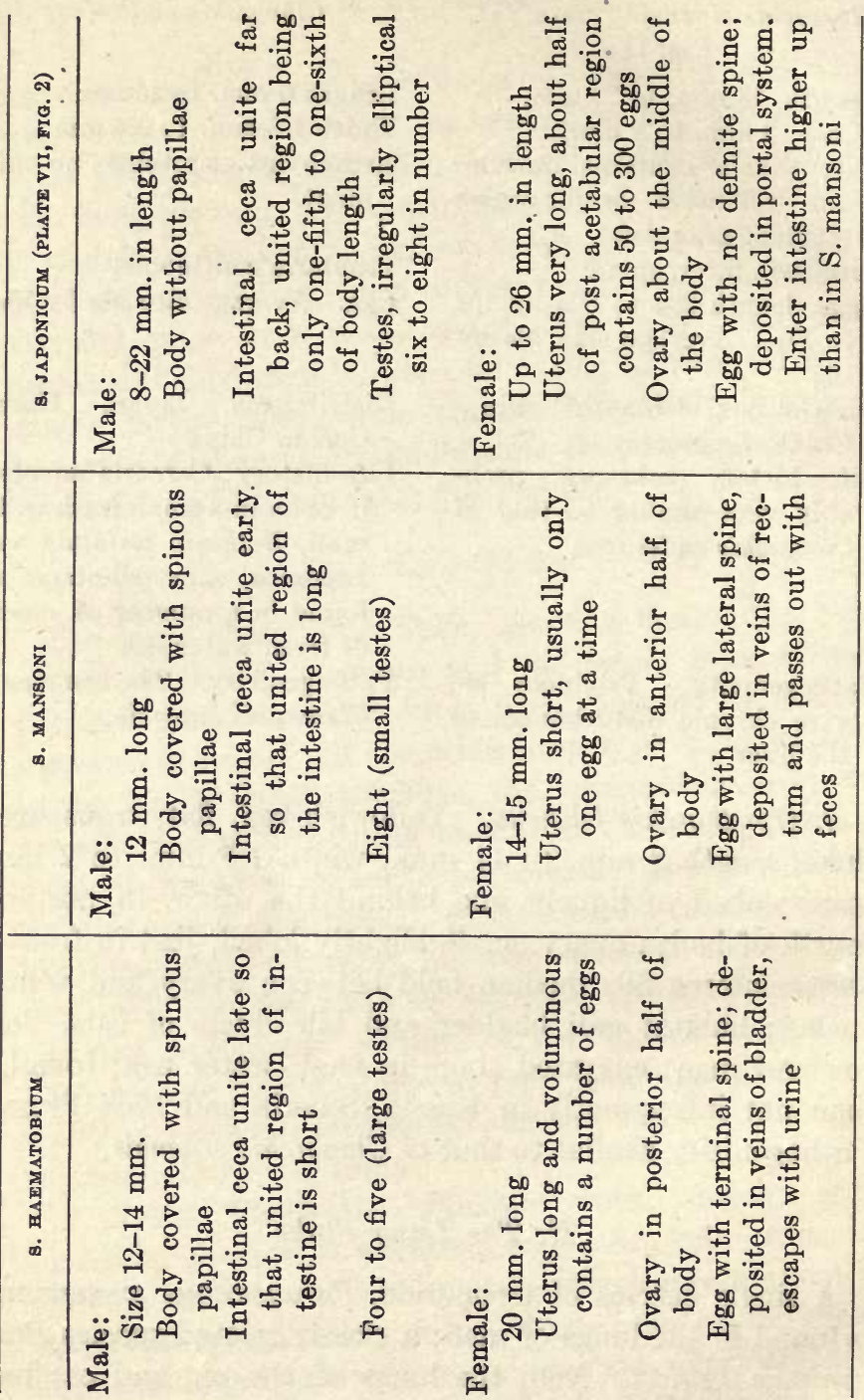




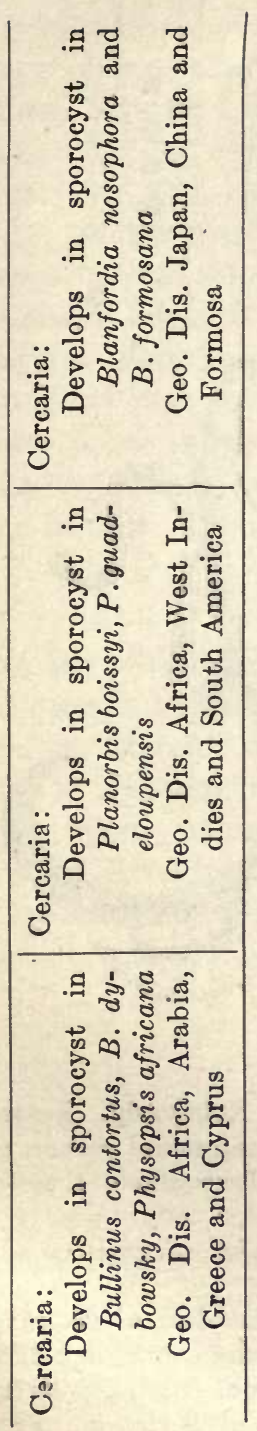



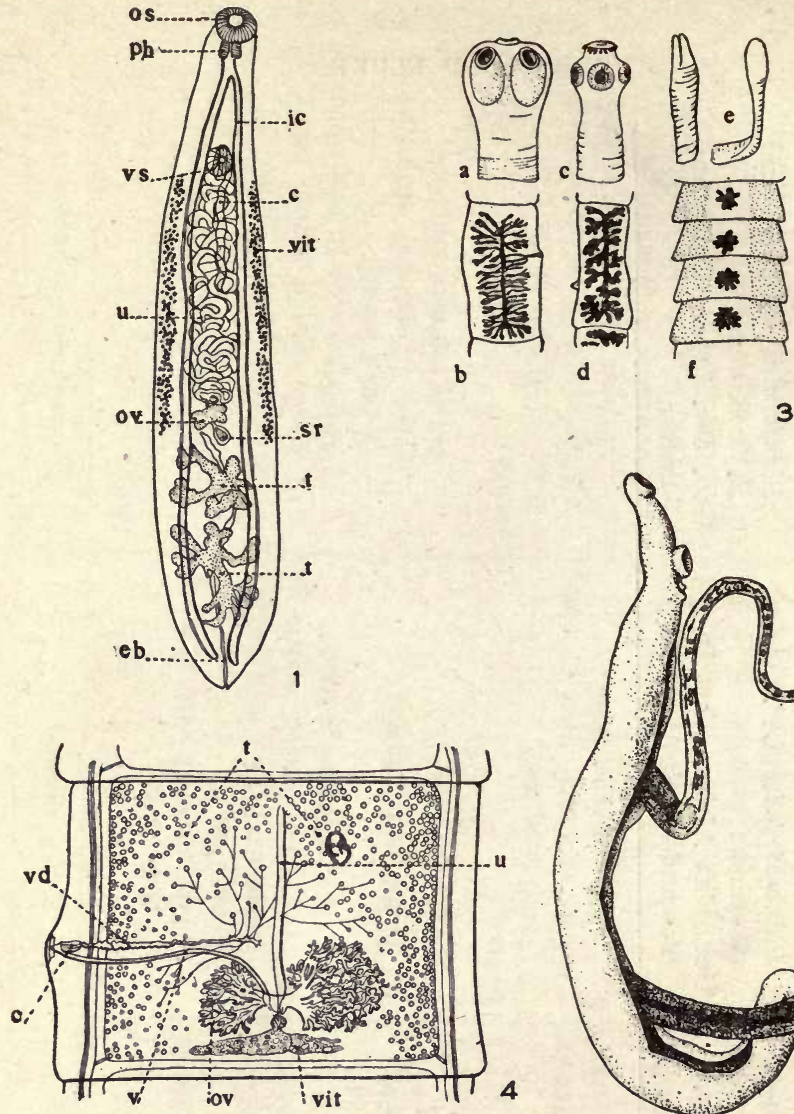

3

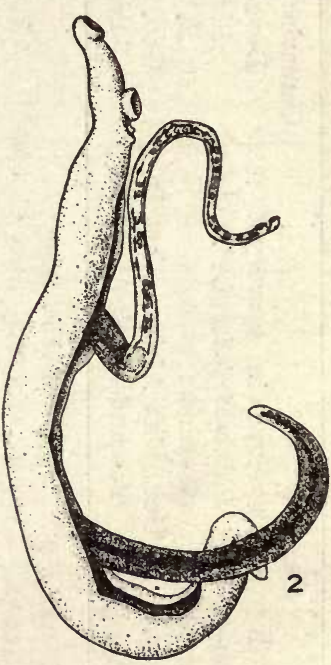

\section{PLATE VII}

Fig. 1. Adult of Clonorchis sinensis. From Kobayashi. Letters used: $c$, cirrus sac; $e b$, excretory bladder; $i c$, intestinal cecum; $o s$, oral sucker; $o v$, ovary; $p h$, pharynx; $s r$, seminal receptacle; $t$, testis; $u$, uterus; $v s$, ventral sucker; vit, vitellaria.

Fig. 2. Adult male and female of Schistosoma japonicum in copula. After Looss.

Fig. 3. Scolices and ripe proglottids of cestodes; a, scolex of Taenia saginata; b, ripe proglottid of T. saginata; c, Scolex of T. solium; d, ripe proglottid of T. solium; e, scolex of Diphyllobothrium latum (Dibithriocephalus latus); f, proglottids of D. latum. From Hertwig after Leuckart, Braun, and Schauinsland.

Fig. 4. Mature proglottid of Taenia saginata. After Sommer. Letters used: $c$, cirrus sac; $o v$, ovary; $t$, testes; $u$, uterus; $v$, vagina, vit, vitellarium. 
Paragonimus westermanii. Color faint reddish brown; shape plump, oval like a coffee grain; length $7.5 \mathrm{~mm}$. to $12 \mathrm{~mm}$., width $4 \mathrm{~mm}$. to $6 \mathrm{~mm}$.; thickness $3.5 \mathrm{~mm}$. to 5 $\mathrm{mm}$.; cuticula covered with spines; acetabulum slightly larger than oral sucker, just in front of the middle of the body; genital pore, just behind acetabulum; habitat lungs, pleura or bronchi of man; dog and cat; cercaria develops species of Melania a common fresh water snail in Japan; encysted stage in land crab or cray-fish; man infected by eating raw crab containing cysts; produces severe pulmonary disturbances which are often complicated with tuberculosis; found in man in Japan, China, Korea, Formosa and Philippine Islands.

\section{F. Blood Flukes}

Genus Schistosoma. Sexes separate; female elongate, enclosed in gynaecophoric canal of male at copulation; no pharynx present; intestinal ceca unite into a single median stem in posterior part of body; cercaria forked-tailed, develops in sporocysts in fresh water snail, and penetrates directly through the skin of the human host; three species have been described from man, i.e., Schistosoma haematobium $S$. mansoni and S. japonicum (Plate VII, Fig. 2). (See page 54.)

\section{Cestoda \\ A. Definition}

Cestodes or tapeworms, ribbon shaped flat worms, divided into segments called proglottids; organ of attachment a scolex with suckers or hooks; no digestive tract present. The human cestodes fall into two different orders; i.e., the Pseudophyllidea and the Cyclophyllidea. 


\section{B. Order Pseudophyllidea}

Cestodes with one or two groove like suckers on the scolex; without proboscis or rostellum; vitellaria are numerous and follicular; a uterine pore present; reproductive organs do not atrophy as the uterus develops; whole segments are not given off when ripe as in the members of the other group; eggs oval with operculum; onchosphere surrounded by ciliated membrane.

Diphyllobothrium latum (Dibothriocephalus latus) is the most important human tapeworm of this group. Three other species of the Pseudophyllidea, D. cordatus, D. parvus and Diplogonoporus grandis, which are probably only incidental in man have been described. Three larval forms of this group (plerocercoids) Sparganum mansoni, Sparganum baxteri and Sparganum proliferum have been reported from the tissues of man.

Diphyllobothrium latum (Dibothriocephalus latus), (Plate VII, Fig. $3 e, f)$, or the fish tape worm. Length 2 to 9 meters; 3,000 to 4,200 proglottids; scolex almond-shaped, $2 \mathrm{~mm}$. to $3 \mathrm{~mm}$. in length with two deep suctorial grooves; proglottids except in posterior third of strobila broader than long; vagina and cirrus open close together on midventral surface; uterine pore just behind other genital pores; eggs given off constantly after maturity and not stored in the uterus; ciliated larva from egg swims freely in water and invades a small crustacean-Cyclops-developing into a procercoid; further development into plerocercoid in muscles of fresh-water fish; man gets infestation by ingesting plerocercoid from raw or partly cooked fish; adult lives in the intestine of cat, dog, fox and man; sometimes produces severe anaemia; centers of distribution are French Switzerland, and the Baltic Provinces of Russia; found also in Italy, Scandinavia, Finland, Turkestan, Japan, Africa, Madagascar and North America. 


\section{Order Cyclophyllidea}

Scolex with four cup or saucer-shaped suckers and in the center an apical organ or rostellum of varied form; no uterine pore; vitellaria compact, single near posterior end of proglottid; proglottids set free after maturity; eggs thin shelled with no operculum, contain onchosphere with one or more membranes.

General discussion. The order Cyclophyllidea contains most of the human tapeworms. Of this group Hymenolepis nana, H. diminuta, Taenia solium, T. sayinata and Echinococcus granulosus ( $T$. echinococcus) are of sufficient importance to be described more fully. Other forms which are incidental in man or insufficiently known are Dipylidium caninum, a common dog tapeworm. Hymenolepis lanceolata, Davainea madagascariensis, Davainea asiatica, Taenia africana, Taenia hominis, T. confusa, and T. bremneri. It is doubtful if all the forms reported from man belonging to the genus Taenia are distinct species; they may simply represent abnormalities of one of the two common species.

1. Genus Hymenolepis. Small worms; proglottids always broader than long; three large testes in each proglottid; genital pores unilateral, uterus persistent, sac-like; eggs round or oval with two or three distinct envelopes.

H. nana

Length 10 to $45 \mathrm{~mm}$. Width 0.5 to $0.7 \mathrm{~mm}$. Scolex globular 0.25 to $0.30 \mathrm{~mm}$. in diameter

Rostellum with a single circlet of 24 to 30 hooks, $14 \mu$ to $18 \mu$ in length

Proglottis up to two hundred in number

Infection direct without intermediate hosts
H. diminuta

Length 20 to $60 \mathrm{~cm}$.

Width up to $3.5 \mathrm{~mm}$.

Scolex 0.2 to $0.5 \mathrm{~mm}$. in diameter

Rostellum rudimentary and unarmed

Proglottis 600-1000

Larval stage a small cysticercoid found in insects 
Common in man; of cosmopolitan distribution. May produce intestinal disturbances especially in children
Common in rats and incidental in $\operatorname{man}$

2. Genus Taenia. Suckers unarmed; uterus with median longitudinal stem and lateral branches; female genitalia in posterior end of proglottid; genital pores irregularly alternating; testes numerous, in front of female genitalia; ovary with two wings; vitellaria behind ovary. Eggs with thin outer membrane and striated thick brown inner shell. Adults in carnivorous mammals and larval stages in herbivorous mammals. Cosmopolitan in distribution.

Taenia solium (Plate VII, Fig. 3 c, d)

Scolex globular about $1 \mathrm{~mm}$. in length

Rosellum with two crowns of hooks

Length 2-8 meters

Number of proglottids $700-1000$

Genital pores irregularly alternating

Branches of uterus in gravid proglottis 5 to 10 in number and dendritic

Proglottids expelled in groups passively with feces

Larval form Cysticercus cellulosae of the pig, sometimes in man
Taenia saginata (Plate VII, Fig. 4 and 3 a, b)

Scolex quadrangular 1.5 to 2 $\mathrm{mm}$.

Rostellum and hooks absent

Length 4-12 meters

Number of proglottidsabout 2000

Genital pores more regularly alternating

Branches of uterus in gravid proglottis $15-30$, dichotomous

Proglottids expelled singly and may force anal sphincter

Larval form Cysticercus bovis in cattle, never found. in man

3. Echinococcus granulosus (Taenia echinococcus). Adult inhabits small intestine of dog, jackall and wolf; measures 2.5 to $6 \mathrm{~mm}$. in length; scolex $0.3 \mathrm{~mm}$. in breadth with a double row of twenty-eight to fifty hooklets on the rostellum; number of segments 3 to 4 , the posterior segment being about 

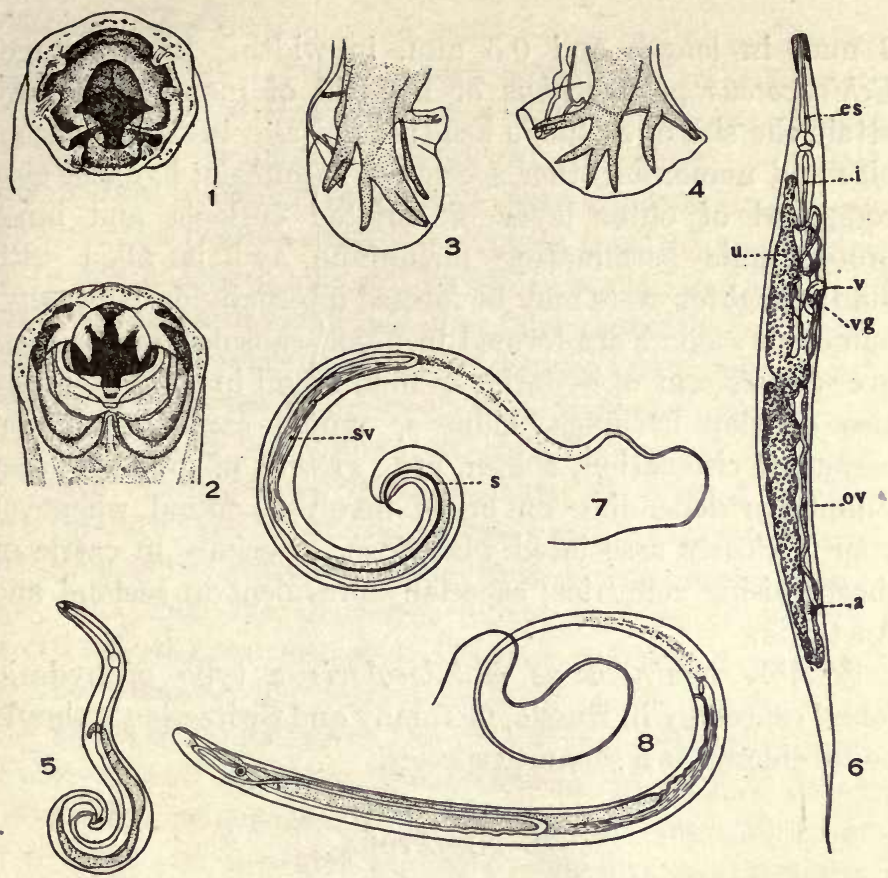

PLATE VIII

Fig. 1. Anterior end of Necator americanus. From Looss.

Fig. 2. Anterior end of Ancylostoma duodenale. From Looss.

Fig. 3. Bursa of Necator americanus. From Looss.

Fig. 4. Bursa of Ancylostoma duodenale. From Looss.

Fig. 5. Adult male of Enterobius vermicularis (Oxyuris vermicularis). From Leuckart.

Fig. 6. Adult female of Enterobius vermicularis (Oxyuris vermicularis). From Leuckart. Letters used: $a$, anus; es, esophagus; $i$, intestine; $o v$, ovary; $u$, uterus; $i$, vulva; $v g$, vagina.

Fig. 7. Adult male of Trichuris trichiura. From Castellani and Chalmers after Claus. Letters used: $s$, spicule; $s v$, seminal vesicle; $t$, testis.

Fig. 8. Adult female of Trichuris trichiura. From Castellani and Chalmers after Claus. 
$2 \mathrm{~mm}$. in length and $0.5 \mathrm{~mm}$. in width. Larval stage, Echinococcus polymorphus or hydatid of man which may attain the size of a child's head; found also in cattle, sheep, pigs and numerous other species of mammals; hydatid cyst composed of outer layer of striated cuticula and inner protoplasmic germinating membrane and is filled with fluid; daughter cysts may be formed internally or externally; numerous scolices are formed in brood capsules within cyst; over 50 per cent of hydatids in man found in the liver; may also develop in lungs, kidneys, cranial cavity, genitalia, organs of circulation, spleen, etc.; growth of cyst produces symptoms depending on organ involved; found whenever man is closely associated with dogs, especially in cattle or sheep raising countries; especially prevalent in Iceland and Australia.

Possibly Echinococcus multilocularis a type of hydatid found especially in Russia, Germany and Switzerland, should be considered as a separate species.

\section{Nematoda}

\section{A. Definition}

Nematodes or round worms, bilaterally symmetrical, unsegmented; digestive system with both mouth and anus; no true coelom but a large body cavity is present between the body wall and digestive tract; sexes separate; body covered with thick cuticula; reproductive organs simple tubular. The nematodes will be taken up according to the families which have human representatives.

\section{B. Family Angiostomidae}

Small nematodes; characterized by heterogeny; each species having a parasitic filariform generation alternating with a bisexual, free-living, rhabditiform generation. 
Strongyloides stercoralis. Parasitic female (Plate VI, Fig. 5), length about $2.2 \mathrm{~mm}$.; width $0.037 \mathrm{~mm}$. to $0.07 \mathrm{~mm}$; cuticula with fine transverse striations; mouth surrounded by four lips; esophagus cylindrical, filariform, one-third body length; anus just in front of pointed posterior extremity; vulva at posterior limit of middle third of body; eggs $50 \mu$ to $58 \mu$ in length and $30 \mu$ to $34 \mu$ in width; usually lie in chain and hatch in small intestine into rhabditiform larvae (Plate VI, Fig. 8); eggs probably produced by parthenógenesis; rhabditiform larvae develop at high temperature $\left(26^{\circ}\right.$ to $35^{\circ} \mathrm{C}$.) in about 30 hours into free living rhabditiform generation of males and females (Plate VI, Figs. 6 and 7); these produce eggs about $70 \mu$ by $45 \mu$ which hatch into a new generation of rhabditiform larvae; these larvae grow in about eight days into the filariform infective larva (Plate VI, Fig. 9); infects man through the skin or mouth and develops into the parasitic filariform female in small intestine; at lower external temperature the free living generation may be omitted and infective larvae develop from first brood of rhabditiform larvae; when present in large numbers produces intestinal catarrh leading to anaemia and intermittant diarrhoea; found everywhere in tropics and sub-tropics where there is sufficient moisture for development of larvae; distribution coincides with that of hookworm but incidence much less.

\section{Family Dracunculidae}

Long threadlike nematodes; male very small in proportion to female; anus absent; ovoviviparous; aquatic crustacean intermediate host necessary for development.

Dracunculus medinensis or the guinea worm. Females, length $50 \mathrm{~cm}$. to $80 \mathrm{~cm}$., width $1.5 \mathrm{~mm}$. to $1.7 \mathrm{~mm}$.; color whitish or yellowish; anterior extremity rounded and bears a cuticular thickening or shield; alimentary canal below 
esophagus atrophied; anus absent; long uterus containing large numbers of free embryos fills most of body; vulva near anterior end; male very poorly known; adult female in subcutaneous tissue of host, producing superficial ulcers through which embryos are extruded; larvae enter small crustacean, cyclops, in water and reach man through ingestion of cyclops; distribution, Africa, Arabia, Persia, Turkestan, Hindustan, Fiji Islands; imported to South America, but only present in a few places.

\section{Family Filaridae}

Long thread like nematodes; anus present; esophagus without bulb; vulva in anterior half of body; two ovaries; generally ovoviviparous; development requires a bloodsucking insect as intermediate host.

General discussion. A large number of different forms have been described from man as belonging to this family. Some are known only in the microfilaria stage and some in an immature stage to which the name agamofilaria is given. A discussion will be given here only of those species which are known in the adult stage, and for which the specific identity seems to be certain.

1. Filaria bancrofti. Worms whitish, long, filiform, cuticula smooth; head globular, terminating in a simple, circular, unarmed, lipless mouth, tail rounded. Male, length 25 $\mathrm{mm}$. to $38 \mathrm{~mm}$. width $0.12 \mathrm{~mm}$.; tail curved or spiral; anus $0.13 \mathrm{~mm}$. from posterior end; guarded by two projecting lips; two unequal curved retractile spicules, larger, $0.6 \mathrm{~mm}$. and smaller, $0.2 \mathrm{~mm}$. in length. Female, length $76 \mathrm{~mm}$. to $100 \mathrm{~mm}$., thickness $0.18 \mathrm{~mm}$. to $0.28 \mathrm{~mm}$.; vulva about $1.2 \mathrm{~mm}$. from anterior end. Adults live in lymphatic glands, larvae (Plate VI, Fig. 3) in blood, appearing in peripheral blood at night; intermediate hosts various species of mos- 
quitoes; produces disturbances of the lymphatic system and is related to elephantiasis; common in Asia, Oceania, West Indies, Central and Tropical South America, Africa; one endemic center in Charleston, South Carolina, U. S. A.

2. Filaria ozzardi (Filaria demarquayi). Female only, known; length $65 \mathrm{~mm}$. to $80 \mathrm{~mm}$.; width $0.21 \mathrm{~mm}$. to 0.25 $\mathrm{mm}$.; vulva $0.76 \mathrm{~mm}$. from anterior tip; head has diameter of $0.1 \mathrm{~mm}$; ; anus $0.25 \mathrm{~mm}$. from posterior end; tail with a pair of characteristic fleshy papillae at tip; adults live in connective tissue; effect on host probably nil; distribution, St. Vincent, Dominica, Trinidad, St. Lucia, British Guiana.

3. Loa loa (Filaria loa). Cuticula with scattered, rounded thickenings or bosses; male thin, white almost transparent, with body tapering to each extremity; length $25 \mathrm{~mm}$. to $34 \mathrm{~mm}$; width $0.27 \mathrm{~mm}$. to $0.43 \mathrm{~mm}$; head like truncated cone; tail somewhat incurved with rounded tip; anus 0.075 $\mathrm{mm}$. to $0.082 \mathrm{~mm}$. from tip of tail; three pairs of well marked preanal papillae and two pairs of post-anal papillae present; spicules unequal $0.113 \mathrm{~mm}$. and $0.176 \mathrm{~mm}$. long; female, length $45 \mathrm{~mm}$. to $63 \mathrm{~mm}$; width $0.5 \mathrm{~mm}$.; vulva situated about $2 \mathrm{~mm}$. from the anterior end; adult in superficial connective tissue - the conjunctiva, the subcutaneous fat, the superficial aponeuroses in all parts of the body; larvae (Plate VI, Fig. 2) only found in peripheral blood during the day; development of larvae takes place in salivary glands of a mango-fly (Crysops dimidiatus); almost entirely limited to Africa; especially West Coast.

4. Acanthocheilonoma perstans (Filaria perstans). Body cylindrical, uniform, except toward both ends where it tapers a little. Male, rarely met with; length $45 \mathrm{~mm}$. width $0.6 \mathrm{~mm}$. to $0.8 \mathrm{~mm}$; tail greatly curved ending in a bifid prolongation of cuticula; spicules very unequal in size; four pairs of pre-anal and two pairs of post-anal papillae present. Female $70 \mathrm{~mm}$. to $80 \mathrm{~mm}$. in length; width 0.12 
mm.; head rounded, neck long; alimentary canal not differentiated into esophagus and intestine; anus opens on a papilla $0.145 \mathrm{~mm}$. in front of posterior tip; vulva $0.6 \mathrm{~mm}$. from anterior extremity; uterus double and when full of eggs and embryos nearly fills body; adults found free in connective tissue at the base of the mesentery around the pancreas, behind the pericardium, and behind the abdominal aorta and suprarenal capsules; microfilariae (Plate VI, Fig. 4) in peripheral blood show no periodicity; life history unknown; effect on host apparently nil; found in tropical Africa and British Guiana.

5. Dirofilaria magalhaesi. Worms white, opalescent, transversely striated; head club-shaped and simple; esophagus with a bulb; tail rounded. Male, length $83 \mathrm{~mm}$. width $0.28 \mathrm{~mm}$. to $0.4 \mathrm{~mm}$.; cloaca $0.11 \mathrm{~mm}$. from posterior tip; two unequal spicules; four pre-anal and three post-anal pairs of papilláe. Female, length $155 \mathrm{~mm}$.; width $0.6 \mathrm{~mm}$., to $0.8 \mathrm{~mm}$.; vulva $2.56 \mathrm{~mm}$. behind anterior tip; anus 0.13 $\mathrm{mm}$. in front of tip of tail.; lives in heart; life history and pathogenicity unknown; found in Brazil.

6. Onchocerca volvulus. Body white filiform, slightly attenuated at the ends; cuticula transversely striated; head rounded; mouth unarmed; alimentary canal straight and undifferentiated. Male, length $30 \mathrm{~mm}$. to $35 \mathrm{~mm}$; width $0.14 \mathrm{~mm}$.; tail strongly recurved and somewhat flattened on its concave aspect; three pairs of papillae present on each side of the anus; three pairs of post-anal papillae; two unequal spicules the larger measuring $0.077 \mathrm{~mm}$. and the smaller $0.082 \mathrm{~mm}$. in length; female, length $60 \mathrm{~mm}$. to 70 $\mathrm{mm}$.; width $0.36 \mathrm{~mm}$; cuticular striations ring like and well marked; tail recurved; vulva $0.76 \mathrm{~mm}$. from the anterior end; found in sub-cutaneous tumors from the size of a pea to that of a pigeons egg; usually found in axilla, popliteal space, about the elbow, in the sub-occipital region and in 
the intercostal spaces; produce lymphangitis and perilymphangitis which is sometimes acute, with fever; embryos found in lymph spaces around the adult worms; life history unknown; found in tropical Africa.

A new species Onchocerca caecutiens has recently been reported from Guatemala; this form is distinguished with difficulty, morphologically, from $\mathrm{O}$. volvulus; it produces tumors and an erysipelas like condition of the head and neck.

\section{E. Family Trichinellidae}

Esophagus, a chain of single cells with intracellular lumen; body divided into attenuated anterior region and thicker posterior region, containing the reproductive organs; ovary single, vulva at junction of anterior and posterior regions.

1. Trichuris trichiura (Plate VIII, Figs. 7 and 8) or the whipworm. Anterior region of the body very long and thread like; the posterior thicker portion truncated with a terminal anus; male, with a spirally rolled posterior end; length $40 \mathrm{~mm}$. to $45 \mathrm{~mm}$; ; single spicule, which lies in a retractile pouch beset with spines, $25 \mathrm{~mm}$. long; female, length $45 \mathrm{~mm}$. to $50 \mathrm{~mm}$.; thicker posterior region equals two-fifths of body length; lives in caecum and sometimes in the vermiform appendix, with its anterior end buried in mucous membrane; infection direct; larvae within the egg require a long period outside of body for development; usually apparently harmless, but at times may give rise to anemia and intestinal disturbances, and occasionally appendicitis; distribution cosmopolitan.

2. Trichinelia spiralis (Trichina spiralis). Male, length $1.4 \mathrm{~mm}$. to $1.6 \mathrm{~mm}$; width $0.4 \mathrm{~mm}$; ; anterior region of body narrowed; orifice of cloaca terminal and lies between two caudal appendages; internal to these are two pairs of papillae, the dorsal one behind the other; female, length $3 \mathrm{~mm}$. to 
$4 \mathrm{~mm}$; width $0.06 \mathrm{~mm}$; anus terminal; vulva in anterior region; lives in adult stage in small intestine of man, pig, wild boar and rat; experimentally it may be introduced into almost any mammal; larvae becomes encysted in muscles of same host as adult; man gains infection by eating raw or partly cooked pork containing these encysted larvae; produces disease known as trichinosis which is very severe when infection is heavy; found everywhere that man eats pork.

\section{F. Family Metastrongylidae}

Bursa in male with true but rather stunted rays; buccal capsule absent or slightly developed; vagina elongate; uteri convergent; parasitic in the respiratory or circulatory systems.

The only species of this family which has been reported from man is Metastrongylus apri, which is a common parasite of the bronchial tubes of pigs. This form has been reported only a few times and is evidently an incidental parasite of man.

\section{G. Family Trichostrongylidae}

Bursa of male large with well developed rays; buccal capsule absent or slightly developed; vagina short; uteri divergent; ovejectors differentiated; parasitic in alimentary canal.

Trichostrongylus,orientalis. Body tapers gradually anteriorly; head with three small lips and blunt or pointed pacillae; cuticula transversely striated; esophagus long; male, length $3.8 \mathrm{~mm}$. to $4.8 \mathrm{~mm}$; spicules spoon like, with a boat shaped accessory piece, $0.11 \mathrm{~mm}$. to $0.13 \mathrm{~mm}$. in length; bursa closed around with large side flaps and without evident median folds; female, length $4.9 \mathrm{~mm}$. to $6.7 \mathrm{~mm}$; vulva in posterior half of body; tail short with two small papillae 
near the tip; parasite of the small intestine; life history unknown; pathogenicity probably nil; common in Japan.

Three other species of this genus, Trichostrongylus colubriformis, $T$. probolurus and $T$. vitrinus which are common parasites of sheep and other ruminants have been reported incidentally from man. These forms are easily overlooked since the adults are very small and the eggs resemble hookworm eggs. It is therefore possible that members of this genus are more common in man than is at present reported. Two other species belonging to this family, Haemonchus contortus and Mecistocirrus fordi (Nematodirus gibsoni) which are common parasites of domestic animals, have been reported incidentally from man.

\section{H. Family Ancylostomidae}

Bursa large with well defined rays; buccal capsule well developed; uteri divergent; parasites of alimentary canal.

1. Sub-family Ancylostominae. Buccal capsule funnelshaped, provided on ventral side with hooks or teeth; bursa of male closed all around; only one-third of dorsal ray cleft; course of genital tubes longitudinal.

Ancylostoma duodenale (Plate VIII, Figs. 2 and 4). Body cylindrical; tapering anteriorly; flesh colored when alive; cuticula ringed; buccal capsule carries ventrally two pairs of hooklike teeth; male, length, about $10 \mathrm{~mm}$; width 0.4 $\mathrm{mm}$. to $0.5 \mathrm{~mm}$; bursa umbrella shaped; rays shown in figure; two slender spicules, about $2 \mathrm{~mm}$. long without barbs; female $12 \mathrm{~mm}$. to $13 \mathrm{~mm}$. in length; vulva behind middle of body; adults live in small intestine; eggs hatch outside body into rhabditiform larvae; grow in 4 to 6 days into the filariform infective larvae, which enter man through skin or by way of the mouth; frequently produces a serious disease, characterized by intestinal disturbances and anemia; 
distribution world wide, in tropical and subtropical regions, where there is sufficient moisture for the development of the larval stages.

Two other species of this genus have been reported from man, Ancylostoma ceylonicun from India and Ancylostoma braziliense from Brazil. Some authorities think that these two forms belong to the same species. They are common parasites of the cat and civet cat and probably only incidental in man.

2. Sub-family Bunostominae. Small buccal capsule, with aperture narrowed anteriorly by plates with cutting edges springing from the sides, and more or less covering the ventral half of the aperture; coils of genital tubes very numerous and close. Externo-dorsal ray thin more especially at the root; spicules of the male barbed at ends.

Necator americanus (Plate VIII, Figs. 1 and 3). Head bent, strongly dorsally, small buccal capsule armed only with semilunar plates: male, $7 \mathrm{~mm}$. to $9 \mathrm{~mm}$. in length and 0.3 $\mathrm{mm}$. to $0.35 \mathrm{~mm}$. in width; bursa shown in figure; spicules long and slender, $0.92 \mathrm{~mm}$. in length and terminate in barbed points; female $9 \mathrm{~mm}$. to $12.6 \mathrm{~mm}$. in length; vulva just in front of middle of body; position in host and life history as in Ancylostoma duodenale.

\section{Family Strongylidae}

Cylindroid rarely filiform bodies; mouth usually with wide buccal capsule and a ring of chitinous armature; esophagus more or less enlarged posteriorly; male with bursa and two equal spicules; females with two ovaries; vulva situated medially or posteriorly; species as rule small.

Termidens diminutus, Oesophagostomum brumpti, $O$. stephanostomum var. thomasi, O..apiostomum, are parasites in the large intestine of man and monkeys in Africa and South 
America. The species of the genus Oesophagostomum are peculiar in that the larvae are often found in tumorous nodules of the intestinal wall. The distribution and prevalence of these forms in man is still insufficiently known.

\section{J. Family Ascaridae}

Large thick nematodes; mouth with three lips, one dorsal and two lateral; esophagus with a bulb; male with two spicules; female with two ovaries; development direct.

Ascaris lumbricoides. Very large worms; male measures 15 to $25 \mathrm{~cm}$. in length and about $3 \mathrm{~mm}$. in diameter; posterior end is conical and hooked ventrally; spicules measure $2 \mathrm{~mm}$. in length are curved and somewhat broadened at their free end; female measures 20 to $40 \mathrm{~cm}$. in length and about $5 \mathrm{~mm}$. in diameter; posterior extremity conical and straight; vulva at junction of anterior and middle thirds of the body; development of larvae in egg requires considerable time; infection direct without intermediate host but with wandering of larvae through the tissues especially lungs before they settle in intestine; may produce intestinal disturbances; wandering of larvae probably produce pulmonary disturbances especially in children; habitat small intestine; cosmopolitan in distribution.

Two doubtful species, Ascaris texana and Ascaris maritima have been described from man. A rare form Lagochilascaris minor has been described from Trinidad, which is easily distinguished from Ascaris lumbricoides by the presence along the lateral lines of cuticular wings extending the whole length of the body. Toxascaris limbata from the dog and Belascaris cati from the cat have been reported a few times from man. 


\section{K. Family Oxyuridae}

Small to medium sized forms; cuticula thickened on each side for the whole length of body in the form of a lateral flange or wing; esophagus long with a well marked bulb containing a valvular apparatus; tail end of female drawn out into a long point; eggs asymmetrical; males much smaller than females, with one spicule.

Enterobius vermicularis (Oxyuris vermicularis) (Plate VIII, Figs. 5 and 6). Pin worm; color white with striated inflation of the cuticula at the anterior end; male 3 to 5 $\mathrm{mm}$. in length; posterior extremity of body is curved ventrally and has six papillae; single spicule, about $70 \mu$ long, hooklike; female, about $10 \mathrm{~mm}$. in length; anus $2 \mathrm{~mm}$. from tip of much attenuated tail; vulva in anterior third of body. Adults in large intestine of man; young forms in posterior part of small intestine and often appendix; infection direct without intermediate host; time of development of larvae in eggs required outside of host very short; in large numbers may produce enterocolitis and appendicitis small numbers produce irritation; distribution cosmopolitan.

An oxyuris like egg has been found in fecal examinations to which the name Oxyuris incognita (Plate V, Fig. 20) has been given. Nothing is known of the adult to which this egg belongs. Recently Syphacia obvelata, a mouse oxyurid has been reported incidentally from man. 



\section{UNIVERSITY OF CALIFORNIA LIBRARY BERKELEY}

Return to desk from which borrowed.

This book is DUE on the last date stamped below.

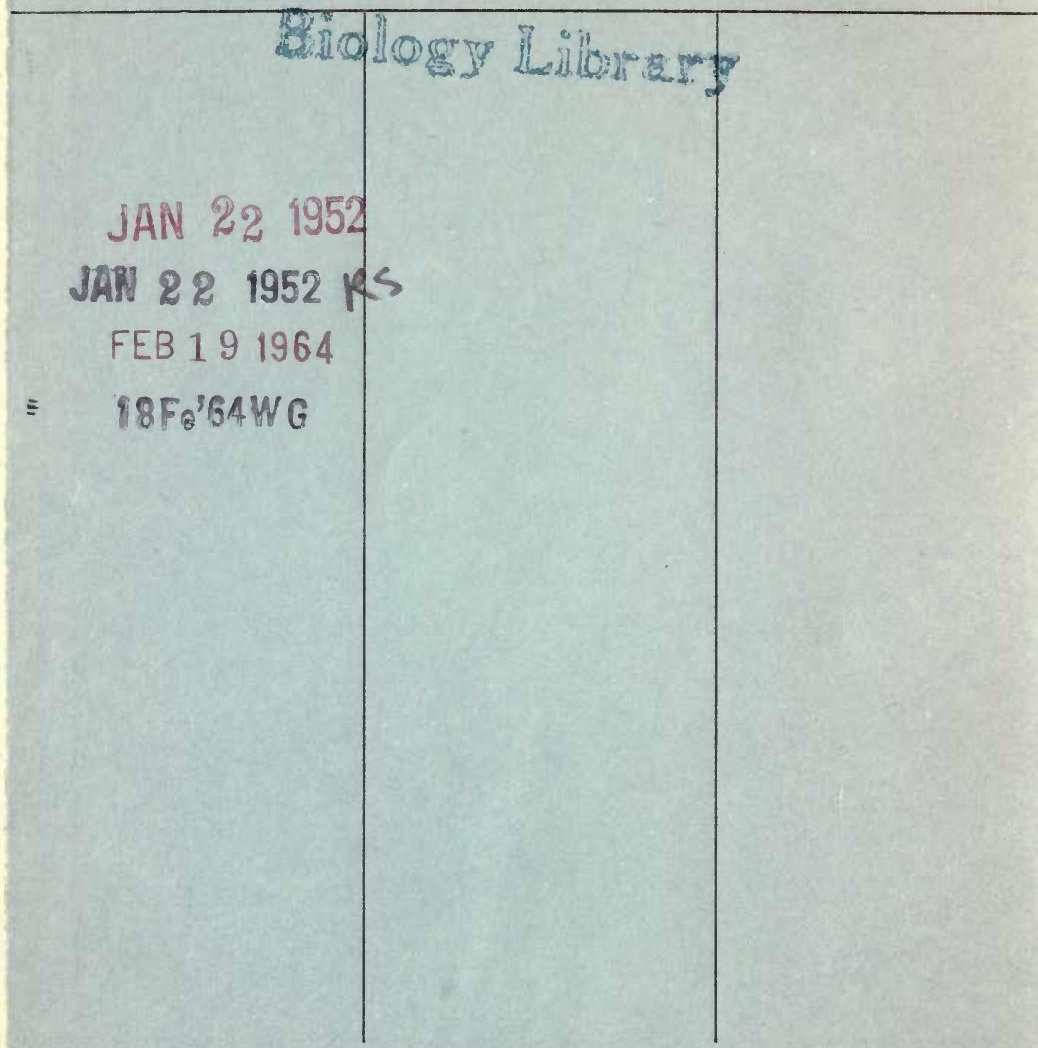



